\title{
Evaluation of MERIS products from Baltic Sea coastal waters rich in CDOM
}

\author{
J. M. Beltrán-Abaunza ${ }^{1}$, S. Kratzer ${ }^{1}$, and C. Brockmann ${ }^{2}$ \\ ${ }^{1}$ Department of Ecology, Environment and Plant Sciences, Stockholm University 106 91, Stockholm, Sweden \\ ${ }^{2}$ Brockmann Consult GmbH, Max-Planck-Str. 2, 21502 Geesthacht, Germany \\ Correspondence to: J. M. Beltrán-Abaunza (jose.beltran@su.se)
}

Received: 26 September 2013 - Published in Ocean Sci. Discuss.: 28 November 2013

Revised: 20 March 2014 - Accepted: 2 April 2014 - Published: 23 May 2014

\begin{abstract}
In this study, retrievals of the medium resolution imaging spectrometer (MERIS) reflectances and water quality products using four different coastal processing algorithms freely available are assessed by comparison against sea-truthing data. The study is based on a pair-wise comparison using processor-dependent quality flags for the retrieval of valid common macro-pixels. This assessment is required in order to ensure the reliability of monitoring systems based on MERIS data, such as the Swedish coastal and lake monitoring system (http://vattenkvalitet.se). The results show that the pre-processing with the Improved Contrast between Ocean and Land (ICOL) processor, correcting for adjacency effects, improves the retrieval of spectral reflectance for all processors. Therefore, it is recommended that the ICOL processor should be applied when Baltic coastal waters are investigated. Chlorophyll was retrieved best using the FUB (Free University of Berlin) processing algorithm, although overestimations in the range 18-26.5\%, dependent on the compared pairs, were obtained. At low chlorophyll concentrations $\left(<2.5 \mathrm{mg} \mathrm{m}^{-3}\right)$, data dispersion dominated in the retrievals with the MEGS (MERIS ground segment processor) processor. The lowest bias and data dispersion were obtained with MEGS for suspended particulate matter, for which overestimations in the range of $8-16 \%$ were found. Only the FUB retrieved CDOM (coloured dissolved organic matter) correlate with in situ values. However, a large systematic underestimation appears in the estimates that nevertheless may be corrected for by using a local correction factor. The MEGS has the potential to be used as an operational processing algorithm for the Himmerfjärden bay and adjacent areas, but it requires further improvement of the
\end{abstract}

atmospheric correction for the blue bands and better definition at relatively low chlorophyll concentrations in the presence of high CDOM attenuation.

\section{Introduction}

Coastal waters are recipients of high inputs of organic matter and nutrients from land, derived from natural processes and human activities (Borges, 2005). This matter and energy exchange between the open sea, coastal waters and land can be observed by changes in the spectra of the water-leaving radiance $\left(L_{\mathrm{w}}\right)$, which is perceived as water colour. The water colour varies according to the prevailing light and physical conditions at the sea surface and depends on the range of concentrations and optical properties of in-water constituents (Prieur and Sathyendranath, 1981; Mobley, 1994). Coastal waters rich in coloured dissolved organic matter (CDOM) represent a challenge for optical remote sensing. CDOM absorption $(\mathrm{aCDOM})$ has a strong impact on the $L_{\mathrm{w}}$ in the visible short wavelengths, which highly influences satellite remote sensing data over coastal and inland waters. The amount of $L_{\mathrm{w}}(443 \mathrm{~nm})$ is approximately $9.8 \%$ of total radiance $\left(L_{\mathrm{t}}\right)$ over open ocean waters measured at the top of the atmosphere, while it is only about $0.4 \%$ for CDOMdominated waters (IOCCG, 2010). Furthermore, the absorption of CDOM near $443 \mathrm{~nm}$ corresponds to the chlorophyll $a$ peak of phytoplankton absorption. The aCDOM, chlorophyll $a$ concentration and suspended matter concentration are water quality parameters of interest for coastal management, and they can be derived from optical remote sensing, 
specifically from MERIS measurement.The dominance of aCDOM in the attenuation of light continues to be a challenge for chlorophyll $a$ retrieval algorithms in ocean colour remote sensing (Carder et al., 1991; Nelson and Siegel, 2013).

In coastal waters, suspended sediment and dissolved organic matter usually do not co-vary with the chlorophyll $a$ concentration (Morel and Prieur, 1977). Different combinations and concentrations of optical constituents may result in the same spectral reflectance signature measured by the sensors, making it difficult to interpret. This, in turn, may hinder accurate retrieval of absorption and scattering properties (i.e. inherent optical properties, IOPs) and subsequent retrieval of concentrations of optical water constituents.

Elaborate methods are required to derive the concentrations of optical variables accurately from space, e.g. matrix or neural network inversion (IOCCG, 2010). Different algorithms have been developed for this task which have been validated against in situ measurements and inter-compared. Of those, the most common coastal processors that are distributed freely were used in this study: the standard MEGS processor (Case- 2 water processing branch), the FUB/WeW processor developed by the Free University Berlin, here referred to as FUB (Schroeder et al., 2007a, b), the Case-2 regional processor C2R (Doerffer and Schiller, 2007) and the boreal water processor (BOREAL) (Doerffer and Schiller, 2008). Each of the above processors (including the Case2 branch of MEGS) use a multiple nonlinear regression method, i.e. a neural network, that includes simulations of radiative transfer models to derive the light propagation through the water and the atmosphere linked with bio-optical models. It must be noted that the FUB processor resolves the water products directly from top-of-atmosphere radiance, whereas the other three processors first derive the level 2 reflectance. The latter is then used to derive IOPs (absorption and scattering), which are subsequently used to derive the level 2 water products.

The combined use of satellites and in situ observations can maximize the benefits of ocean colour observations (Gregg and Conkright, 2001). Currently, only three satellite ocean colour sensors have about 10 years of global coverage of data, i.e. SeaWiFS (1997-2011, NASA), MODIS (1999ongoing, NASA) and MERIS (2002-2012, ESA). MERIS was especially adapted for coastal applications. It had high spatial resolution $(290 \mathrm{~m} \times 260 \mathrm{~m})$ and spectral resolution $(15$ spectral channels in the visible and near-infrared region), compared to the other sensors (Doerffer et al., 1999; European Space Agency, 2011). However, contact with the ENVISAT spacecraft was lost in April 2012, and hence transmission of MERIS data was no longer possible. The current focus of the ENVISAT mission is to encourage data exploitation of the 10-year satellite data archive and to upgrade and validate image processing algorithms in order to derive the geophysical products (level 2 processing) accurately (Laur, 2012). This will lead to improved algorithms for the operational follow-up mission of MERIS, Sentinel-3 (the launch is planned in November 2014), which will carry the Ocean Land Colour Instrument (OLCI) that has improved characteristics compared to MERIS; e.g. a spectral resolution of 21 wavelength bands in the range $400-1020 \mathrm{~nm}$.

The small number of in situ data available in optically complex waters to train "global" algorithms, supports the requirement for "regional" algorithms as a complement (Kajiyama et al., 2013). In the study of Zibordi et al. (2013), the standard products of 3 rd reprocessing MERIS data sets were evaluated for European seas. Their study reinforces the need to substantially increase the number of highly accurate and globally distributed in situ measurements to adequately address regional uncertainties that affect ocean colour data products. On a regional level, Kratzer et al. (2008) showed that the FUB processor was best for retrieving level 2 products from the Himmerfjärden area, including the NW Baltic Proper. The FUB has also been applied successfully in other areas of the Baltic Sea (Ohde et al., 2007; Vaičiūtè et al., 2012). Kratzer and Vinterhav (2010) showed that the retrieval of level 2 products over Swedish coastal waters was improved by using a combination of the Improved Contrast between Ocean and Land (ICOL) processor (Santer and Zagolski, 2007, 2009), correcting for adjacency effects, and the FUB processor. An independent end-user survey also tested the results of different processing schemes in coastal and lake areas (Philipson et al., 2009). All end-users confirmed that the images that had been processed with ICOL and FUB represented best the ranges of water quality parameters for the respective water body (Swedish great lakes and Himmerfjärden area) and season. The processing chain ICOL-FUB was therefore applied to the operational monitoring system (http://vattenkvalitet.se) for the Swedish great lakes and the coastal areas.

At the end of 2011, ESA completed the definition and implementation of the third reprocessing algorithms (Bourg and Members of the MERIS Quality Working Group, 2011). At that time a new version of ICOL was also made available (v. 2.9.1). Therefore, the previous results need to be reassessed in order to confirm that they are still valid, or if a change is required in the processing chain of the operational system in order to secure its reliability. Here, a study that assesses the most common MERIS processors for coastal waters (using MERIS 3rd reprocessing data against sea-truthing data) is presented. An increased number of matchup data was available, including data from the spring season (2010). This new study also includes the assessment of accuracy of aCDOM retrieval, which could not be performed before because of the lack of available in situ measurements of aCDOM (Kratzer and Vinterhav, 2010). Besides the further development of MERIS processing, the algorithm to retrieve the MERIS reflectance for the in situ radiometer (TACCS) used for validation was also improved (Zibordi et al., 2012) in comparison with the previous study done by Kratzer and Vinterhav (2010). The aim of the present study is to make 
processing recommendations for the current monitoring system, based on MERIS data 3rd reprocessing, to identify the advantage of the different MERIS processors for the retrieval of water quality parameters in the Baltic Sea and, furthermore, to make recommendations for future satellite missions such as Sentinel-3, which is planned to be launched by ESA at the end of 2014.

\section{Data and methods}

\subsection{Study area}

The region of interest is on the northwestern coast of the Northern Baltic Proper (Fig. 1), south of Stockholm Archipelago, including Himmerfjärden bay and its adjacent areas, top-left latitude and longitude $\left(60^{\circ} \mathrm{N}, 17^{\circ} \mathrm{E}\right)$ and bottom-right coordinates $\left(58^{\circ} \mathrm{N}, 19^{\circ} \mathrm{E}\right)$. This region is a brackish marine ecosystem (Elmgren, 2001). The influence of tides is negligible in most of the Baltic Sea, therefore the main circulation is driven by the surface wind speed and changes in atmospheric pressure (Leppèaranta and Myrberg, 2009). The Baltic Sea and Himmerfjärden are optically dominated by CDOM absorption (Kutser et al., 2009; Kratzer and Tett, 2009).

Himmerfjärden bay follows a regular phenology of phytoplankton blooms that occur in the Baltic Sea during spring and summer. The summer blooms are of special environmental and health interest because they are dominated by the potentially toxic nitrogen-fixing filamentous Cyanobacteria, Nodularia spumigena and non-toxic Aphanizomenom $\mathrm{sp}$. The chlorophyll $a(\mathrm{Chl} a)$ concentrations that can be observed within Himmerfjärden range from 1 up to $18 \mathrm{mg} \mathrm{m}^{-3}$, with higher values during the spring bloom. The suspended particulate matter (SPM) load ranges from 0.5 up to $2.7 \mathrm{~g} \mathrm{~m}^{-3}$ with decreasing values towards the open sea (Kratzer and Tett, 2009). The absorption of CDOM (g440) in Himmerfjärden ranges from 0.39 up to $1.27 \mathrm{~m}^{-1}$, and in the open sea from about 0.3 to $0.5 \mathrm{~m}^{-1}$. The Himmerfjärden region has a local catchment area of $536 \mathrm{~km}^{2}$ receiving a minor freshwater outflow from Lake Mälaren (Franzén et al., 2011). Located within the Himmerfjärden bay (Fig. 1) is the third largest sewage treatment plant in the Stockholm region. From 2007 to 2010 an adaptive management experiment was carried out in the Himmerfjärden sewage treatment plant (HSTP) to study the effects of nitrogen release on eutrophication and the development of cyanobacterial blooms. The experiment entailed effluent release without nitrogen treatment during 2007-2008, and with full-capacity nitrogen treatment during 2009-2010.

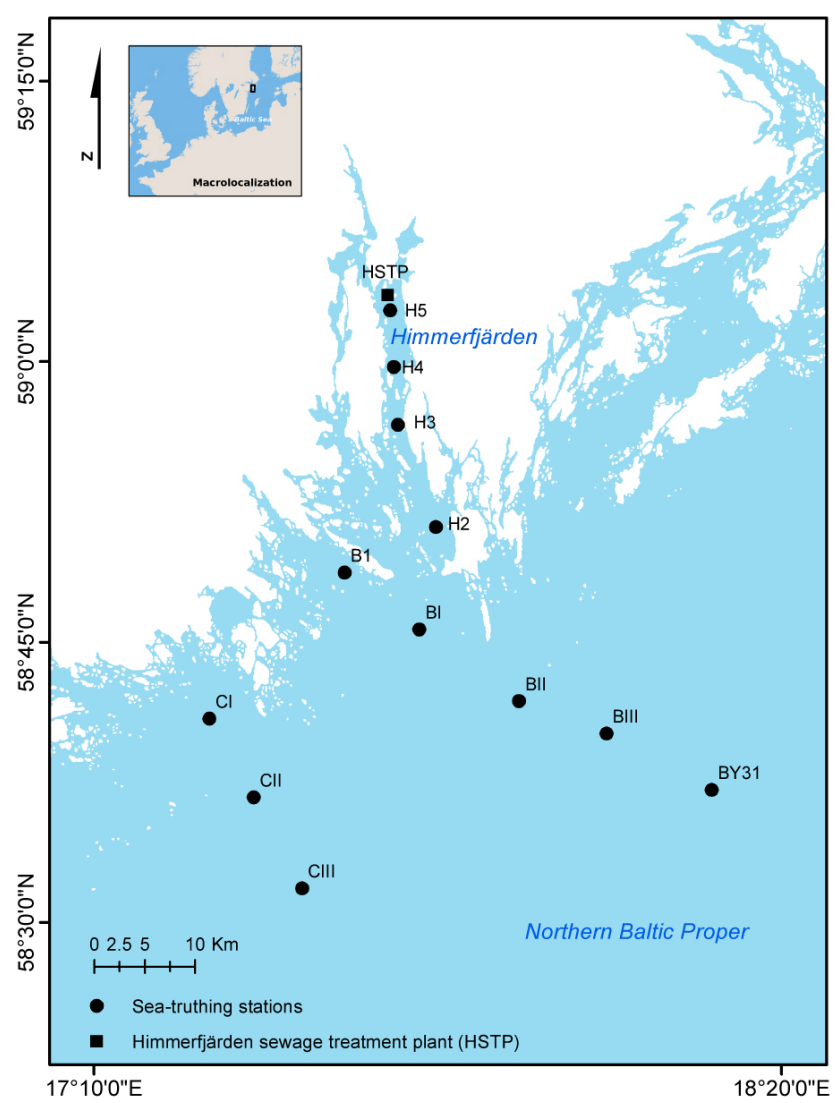

Figure 1. Himmerfjärden is the region of interest, where seatruthing campaigns were performed in 2008 and 2010. See Table 1 for campaign dates and time of the satellite overpasses.

\subsection{Sea-truthing data}

\subsubsection{Water samples}

The sea-truthing data were gathered during two monthly field campaigns in July 2008 and spring 2010 (with one additional transect in August 2008, Table 1). Water samples were taken in Himmerfjärden bay as well as along two transects offshore. Usually, 3-4 stations can be sampled per transect in 1 day. The sampling also includes measuring Secchi depth by using a water telescope from deck. The starting time for the sampling usually began $1-2 \mathrm{~h}$ before the MERIS overpass (Table 1). For the validation of satellite data, water samples were taken from just below the surface using a sampling bucket. Water sampling takes always triplicates of SPM (at all stations) and for chlorophyll (at all satellite overpass stations). For CDOM it was shown during previous sampling that triplicates are not needed as the standard deviation is zero (Kratzer, 2000). In order to optimize the sea-truthing measurements, a balance had to be found between number of stations sampled within a $2 \mathrm{~h}$ matchup window, and number of replicates per sampled station. 
Table 1. Matchup timetable. Note: Cast ID refers to the site, number of transect, and sampling ID.

\begin{tabular}{|c|c|c|c|c|c|c|c|c|}
\hline \multirow[b]{2}{*}{ Cast ID } & \multirow[b]{2}{*}{ Date } & \multicolumn{2}{|c|}{ Time [UTM] } & \multirow[b]{2}{*}{ Cloudy } & \multicolumn{4}{|c|}{ MERIS matchup window } \\
\hline & & In situ & Overpass & & $<30 \min$ & $\leq 1 \mathrm{~h}$ & $\leq 2 \mathrm{~h}$ & $\gg 2 \mathrm{~h}$ \\
\hline BIII_1a & 9 Jul 2008 & 09:14:00 & $09: 25: 41$ & & $*$ & & & \\
\hline $\mathrm{H} 3 \_2 \mathrm{~b}$ & & 09:45:00 & 09:37:05 & & $*$ & & & \\
\hline $\mathrm{H} 4 \_2 \mathrm{c}$ & & 10:45:00 & 09:37:05 & & & $*$ & & \\
\hline H5_3a & 18 Jul 2008 & 08:03:00 & $09: 42: 46$ & & & & $*$ & \\
\hline $\mathrm{H} 4 \_3 \mathrm{~b}$ & & 09:00:00 & $09: 42: 46$ & & & $*$ & & \\
\hline $\mathrm{H} 3 \_3 \mathrm{c}$ & & 09:45:00 & $09: 42: 46$ & & $*$ & & & \\
\hline $\mathrm{H} 2 \_3 \mathrm{~d}$ & & $10: 45: 00$ & $09: 42: 46$ & & & $*$ & & \\
\hline BY31_4a & $24 \mathrm{Jul} 2008$ & 08:50:00 & 09:54:08 & & & $*$ & & \\
\hline BIII_4b & & 09:55:00 & 09:54:08 & & $*$ & & & \\
\hline BII_4c & & $10: 45: 00$ & 09:54:08 & & & $*$ & & \\
\hline BI_4d & & 11:30:00 & 09:54:08 & & & & $*$ & \\
\hline CI_5a & $25 \mathrm{Jul} 2008$ & 08:30:00 & $09: 22: 50$ & & & $*$ & & \\
\hline CII_5b & & 09:15:00 & 09:22:50 & & $*$ & & & \\
\hline CIII_5c & & 10:10:00 & $09: 22: 50$ & & & $*$ & & \\
\hline H4_6a & 28 Jul 2008 & 09:45:00 & 09:28:32 & & $*$ & & & \\
\hline H3_6b & & $10: 35: 00$ & 09:28:32 & & & $*$ & & \\
\hline $\mathrm{H} 2 \_6 \mathrm{c}$ & & 11:20:00 & 09:28:32 & & & & $*$ & \\
\hline $\mathrm{H} 2 \_7 \mathrm{a}$ & $30 \mathrm{Jul} 2008$ & 08:34:00 & $10: 05: 28$ & & & & $*$ & \\
\hline CIII_8a & $31 \mathrm{Jul} 2008$ & 08:30:00 & 09:33:33 & & & $*$ & & \\
\hline CII_8b & & $10: 45: 00$ & $09: 33: 33$ & & & & $*$ & \\
\hline CI_8c & & 08:30:00 & $09: 33: 33$ & & & $*$ & & \\
\hline B1_1a & 5 May 2010 & 08:44:00 & 09:24:41 & $*$ & & $*$ & & \\
\hline $\mathrm{H} 2 \_1 \mathrm{~b}$ & & $11: 30: 00$ & $09: 24: 41$ & & & & $*$ & \\
\hline BI_2a & 11 May 2010 & 08:30:00 & 09:36:08 & & & $*$ & & \\
\hline BII_2b & & 09:45:00 & 09:36:08 & & $*$ & & & \\
\hline BIII_2c & & $11: 05: 00$ & 09:36:08 & & & & $*$ & \\
\hline B1_3a & 18 May 2010 & 07:57:00 & 09:16:04 & $*$ & & & $*$ & \\
\hline BI_3b & & $10: 12: 00$ & 09:16:04 & & & $*$ & & \\
\hline BII_3c & & $12: 27: 00$ & 09:16:04 & & & & & $*$ \\
\hline BI_4a & 20 May 2010 & 08:01:00 & 09:53:22 & $*$ & & & $*$ & \\
\hline BII_4b & & 09:25:00 & 09:53:22 & $*$ & $*$ & & & \\
\hline BIII_4c & & $10: 32: 00$ & 09:53:22 & * & & $*$ & & \\
\hline BY31_4d & & $11: 35: 00$ & 09:53:22 & & & & $*$ & \\
\hline B1_5a & 24 May 2010 & $08: 15: 00$ & 09:27:34 & & & & $*$ & \\
\hline $\mathrm{H} 2 \_5 b$ & & 09:25:00 & 09:27:34 & & $*$ & & & \\
\hline H3_5c & & 10:46:00 & $09: 27: 34$ & & & $*$ & & \\
\hline $\mathrm{H} 4 \_6 \mathrm{a}$ & 20 Aug 2010 & 08:20:00 & 10:02:02 & $*$ & & & $*$ & \\
\hline $\mathrm{H} 2 \_6 b$ & & 10:10:00 & 10:02:02 & & $*$ & & & \\
\hline B1_6c & & $11: 30: 00$ & $10: 02: 02$ & $*$ & & & $*$ & \\
\hline
\end{tabular}

Concentrations of organic and inorganic SPM were measured by the gravimetric method (Strickland and Parsons, 1972). This method has an error of $10 \%$ to derive total SPM in summer from surface water samples in the Baltic Sea (Kratzer, 2000). For the determination of aCDOM, the water was filtered through $0.2 \mu \mathrm{m}$ membrane filters and measured spectrophotometrically in a $10 \mathrm{~cm}$ optical cuvette in a Shimadzu UVPC 2401 dual beam spectrophotometer. The optical density (OD), which is equivalent to absorbance at $440 \mathrm{~nm}$, was corrected for the OD at $750 \mathrm{~nm}$. The absorption at $440 \mathrm{~nm}$ was derived as described in Kirk (1994) and Kratzer (2000). For the estimation of chlorophyll $a$ 
(Chl $a$ ), the trichromatic method was applied (Jeffrey and Humphrey, 1975; Parsons et al., 1984). The samples were filtered through GF/F filters and kept in liquid nitrogen until they were analysed. They were then extracted into $90 \%$ acetone using sonication. The trichromatic method has an error of $7 \%$ when deriving Chl $a$ from the Baltic Sea. The percentage error of the in situ values (i.e. SPM, Chl $a$ ) correspond to the coefficient of variation (i.e. standard deviation/mean), using all the available samples from different bottles (Kratzer, 2000). During 2002, an international chlorophyll inter-calibration exercise was coordinated by the Norwegian Institute of Water Research (NIVA) for the European MERIS Validation Team (MVT) (Sørensen et al., 2007). The results of the MVT inter-calibration showed that the spectrophotometric Chl $a$ measurements of natural water samples by the marine remote sensing group from Stockholm University were within $8.6 \%$ of the median value of the international group. In previous tests the method to derive aCDOM had shown much less variability between replicates from different bottles (Kratzer, 2000), than for SPM and Chl $a$, and in this study it is assumed to be well below $5 \%$.

\subsubsection{Field radiometry}

The Tethered Attenuation Coefficient Chain-Sensor (TACCS, manufactured by Satlantic Inc., Canada) is an in-water radiometer deployed on a floating buoy. The TACCS has an in-water up-welling radiance sensor $\mathrm{Lu}(\lambda)$ with a full-angle field of view (FAFOV) of $20^{\circ}$ at nominal depth $0.5 \mathrm{~m}$. The $\mathrm{Lu}$ sensor has seven channels matching the MERIS bands centred at 412, 443, 490, 510, 560, 620 and $665 \mathrm{~nm}$. The TACCS includes an in-air downward irradiance sensor Ed centred at 443, 490 and $670 \mathrm{~nm}$. The TACCS also includes an in-water chain of $\operatorname{Ed}(\lambda=490 \mathrm{~nm})$ at the nominal depths of 2, 4, 6 and $8 \mathrm{~m}$. All sensors have a $10 \mathrm{~nm}$ bandwidth. TACCS measurements were logged in $3 \mathrm{~min}$ intervals at an acquisition rate of $0.5 \mathrm{~Hz}$ and approximately at $20 \mathrm{~m}$ distance from the ship to avoid ship shading.

Coincident optical profiles were taken with the TACCS using an $\mathrm{AC} 9+$ from WET Labs, measuring spectral absorption $a$ and beam attenuation $c$ at 412, 440, 488, 510, 532, 555, 630, 676 and $715 \mathrm{~nm}$ as described in Kratzer et al. (2008). By using the TACCS and AC9+ data, the sea surface reflectance $\rho_{\mathrm{w}}$ is derived by following Eq. (1) (Kratzer et al., 2008; Zibordi et al., 2012), and used for the validation of the MERIS reflectance data:

$\rho_{\mathrm{w}}(\lambda)=\frac{\pi \times L_{\mathrm{u}}\left(0^{+}, \lambda\right)}{E_{\mathrm{s}}(\lambda)}$,

where $L_{\mathrm{u}}$ is the spectral upwelling radiance interpolated just above the surface $\left(0^{+}\right)$and $E_{\mathrm{S}}$ is the downwelling incident spectral irradiance.

The uncertainties for the TACCS processor used in the study is within $7 \%$ in the blue-green bands, and $8 \%$ in the red (Zibordi et al., 2012). The TACCS processor is described in the MERIS optical measurements protocols Barker (2011).

During each field campaign, quick looks of the Advanced Very High Resolution Radiometer (AVHRR) data from the Swedish Meteorological and Hydrological Institute (SMHI) were used to specifically avoid surface accumulations of Cyanobacteria in order to assure minimum horizontal optical heterogeneity of the water body. Furthermore, daily meteorological forecasts were used for planning the sea-truthing campaigns and for avoiding transect days with high wind speeds and/or cloudy conditions. Here, it is assumed that the natural spatial and temporal variability of the sea surface reflectance remains without significant changes for the selected time window of the matchup with the satellite.

A prototype processor to derive reflectance from TACCS data was described in Kratzer et al. (2008) and used for the validation of reflectance data in Kratzer and Vinterhav (2010). During 2010-2012, a new TACCS processor was developed in order to improve the retrieval of reflectance and to describe the uncertainties involved (Moore et al., 2010; Zibordi et al., 2012), which allows an improved assessment of MERIS data against sea-truthing measurements. In this study, the latest processor as described in Zibordi et al. (2012) and the respective calibration files were used to process the TACCS data from both years 2008 and 2010.

\subsection{Satellite data processing considerations}

\subsubsection{Level 1b processing}

Prior to field campaigns, the overpass times of ENVISAT were predicted by using the Earth observation swath and orbit visualization tool next-generation software (ESOV-NG version 2.0). These dates were then used for the booking of ship time for validation against in situ measurements. A data set consisting of 14 MERIS full-resolution (FR) level 1b scenes (3rd reprocessing) was acquired for the study area that coincided with the field measurements of two sea-truthing campaigns (Table 1). The time difference between in situ measurements and the MERIS overpass was less than $2 \mathrm{~h}$ for most of the stations investigated here.

The accurate MERIS ortho-rectified geo-location operational software (AMORGOS-version 4.0p1) was used to improve the location accuracy in the level 1b MERIS data set. AMORGOS improves the geo-location of MERIS FRS products by using accurate satellite attitude and orbit files and the GETASSE 3.0 Digital Elevation Model (DEM) to generate three new bands, latitude, longitude and altitude, for each MERIS pixel which results in a MERIS product mode called full swath geo-corrected (FSG) (ACRI-ST, 2011). The AMORGOS tool was also used in this study for sub-setting the MERIS data sets. The total number of lines to process was reduced to 577 with AMORGOS. This is a clipping operation over the region of interest which serves two purposes: (1) it preserves the ENVISAT file format (.N1 file) 
as required by the ODESA CFI software (ACRI-ST, 2012), and (2) it facilitates the application of the ICOL processor to correct for adjacency effects (Santer and Zagolski, 2009) by using a smaller image size, and also preserves the ENVISAT file format.

The MERIS FSG data sets were then batch processed using the graph-processing framework (GPF) of the Earth Observation Toolbox and Development Platform (BEAM, version 4.10.3) software. A cloud mask was generated for the MERIS FSG data set using BEAM with the cloud probability processor version 1.5.203 including the advanced landwater mask. The cloud probability processor uses two artificial neural nets that provide a cloud probability value in the range of $0-1$. The pixel value is set as cloudy when the probability value $>80 \%$, cloud free (probability $<20 \%$ ) or where it is uncertain $(20 \%<$ probability $<80 \%)$.

The level $1 \mathrm{~b}$ data set, using standard procedures, was also corrected for systematic radiometric differences within the detector of the five cameras that cover the swath of the MERIS FRS images to reduce the "vertical striping" by radiometric equalization of coherent noise (Bouvet and Ramino, 2010). The satellite data were also corrected for the variations of the spectral wavelength of each pixel along the image, the so-called "smile effect" correction, resulting in a reduction of disturbances at camera borders (MERIS_ESL, 2008). The smile correction (SC) and the equalization of coherent noise (EQ) are implemented in the MERIS level $1 \mathrm{~b}$ radiometry correction operator version 1.1 available in BEAM.

The land adjacency effects in the study area were corrected for by using the ICOL 2.9.1 processor. Two MERIS level 1b processed data sets were then produced. Both data sets included the SCEQ corrections as default, but only one data set was ICOL corrected. This study will use the acronym "L1N" to indicate that ICOL has been applied. Furthermore, a separate MERIS level $1 \mathrm{~b}$ data set was kept for further processing with the MERIS Ground Segment Development Platform (MEGS) standard level 2 processor version 8.1. This data set includes only EQ correction with and without ICOL. The smile correction was not applied to the input data for MEGS, because MEGS includes the smile correction as a default. Table 2 shows the level $1 \mathrm{~b}$ processing schemes used for the MERIS data sets comparison.

\subsubsection{Level 2 processing}

The standard MEGS processor (Case-2 water processing branch, Doerffer and Schiller, 1997; Doerffer, 2011) and three coastal processors that are provided as source-free plug-ins for the BEAM software, were used to derive the geophysical products (level 2 processing): the FUB processor (Schroeder et al., 2007a, b), the Case-2 regional processor C2R (Doerffer and Schiller, 2007) and the boreal lakes water processor BOREAL (Doerffer and Schiller, 2008). The general processing work flow can be seen in Fig. 2. The processors assume environmental conditions of infinite deep water

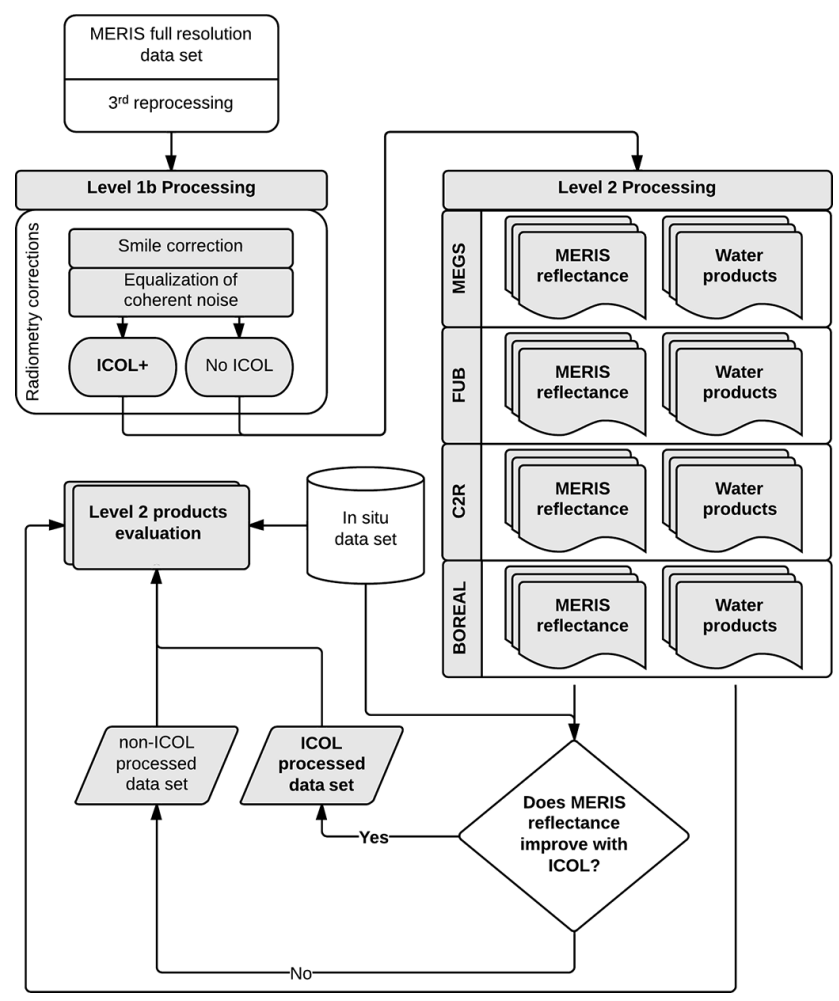

Figure 2. Flow chart of the data processing work flow.

with vertical homogeneous distribution of water constituents, and no inelastic scattering or polarization effects are considered. The derived geophysical products for each processor used for the evaluation included algal pigments considering chlorophyll $a$ as a proxy for biomass, here referred to as CHL, suspended particular matter and aCDOM (yellow substances). The yellow substances product (yellow_subs) of MEGS, C2R, BOREAL is the sum of yellow substance at $443 \mathrm{~nm}$ (YS) and the bleached particulate absorption (BPA) (Doerffer and Schiller, 1997; Doerffer, 2002; Doerffer and Schiller, 2007). In FUB this is referred to as yellow substance (Schroeder et al., 2007b). However, due to the relatively high aCDOM in the Baltic Sea in relation to non-pigmented particles (Babin, 2000; Kowalczuk et al., 2006), in this study it is assumed that yellow substance mostly refers to the absorption of $\mathrm{CDOM}$, and that $\mathrm{aCDOM} \gg \mathrm{BPA}$.

The radiometry measured in situ is limited to the first seven bands of MERIS. Therefore, only the MERIS reflectance $\rho_{\mathrm{w}}(\lambda)$ at $412,443,490,510,560,620$ and $665 \mathrm{~nm}$ estimated by each processor was used in this study. The ranges of concentrations of optical properties used for training the FUB processor are described in Schroeder et al. (2007b) and Zhang (2003). The range of optical properties parameterizing MEGS and C2R are given in Doerffer and Schiller (2007) and Doerffer (2011). The parameterization range for BOREAL can be found in Koponen et al. (2008). The concentration ranges of the respective processors are summarized in Table 3. 
Table 2. Level $1 \mathrm{~b}$ processing schemes applied.

\begin{tabular}{ll}
\hline Acronym & Description \\
\hline SC & Smile correction \\
EQ & Equalization of coherent noise \\
SCEQ_L1N & Data set with both SCEQ corrections where ICOL has been applied \\
SCEQ_X & Data set with both SCEQ corrections where ICOL has not been applied \\
\hline
\end{tabular}

Table 3. Ranges of optical water constituent concentrations that define the training range of level 2 processors used here.

\begin{tabular}{lrrrrrrrr}
\hline water constituent & $\begin{array}{r}\text { FUB } \\
\text { Min }\end{array}$ & Max & $\begin{array}{r}\text { MEGS } \\
\text { Min }\end{array}$ & Max & $\begin{array}{r}\text { C2R } \\
\text { Min }\end{array}$ & Max & BOREAL & Max \\
\hline$\left[\mathrm{CHL}, \mathrm{mg} \mathrm{m}^{-3}\right]$ & 0.05 & 50 & 0.02 & 43 & 0.003 & 50 & 0.5 & 50 \\
\hline$\left[\mathrm{SPM}, \mathrm{g} \mathrm{m}^{-3}\right]$ & 0.05 & 50 & 0.01 & 51 & 0.03 & 50 & 0.1 & 20 \\
\hline${ }_{\mathrm{aCDOM}_{440}, \mathrm{~m}^{-1}}$ & 0.005 & 1.0 & 0.005 & 5 & 0.002 & 2 & 0.25 & 10 \\
\hline
\end{tabular}

\subsection{Macro pixel quality and exclusion criteria}

Along the Swedish coast the typical current velocity in the Baltic Sea ranges from 2 to $5 \mathrm{~cm} \mathrm{~s}^{-1}$ (Maslowski and Walczowski, 2002). Considering $5 \mathrm{~cm} \mathrm{~s}^{-1}$ to be a fastmoving current in the study area, the water mass may move a maximum of $180 \mathrm{~m}$ in 1 hour, and in 2 hours the water mass may thus move about one MERIS pixel. A matrix of $3 \times 3$ pixels centred at the field sample location has been used to cover the natural variability of water displacement. Therefore, only those casts that were sampled during a matchup time window within the satellite overpass of $2 \mathrm{~h}$ or less (Table 1) have been selected for validation.

Each processor can raise flags at different stages of processing. These flags provide additional information regarding surface type (i.e. land, water, cloud); they also provide confidence information when the algorithm input or output is outside the expected range. Therefore, the macro pixels that represent water were filtered by flags, and pixels within the macro pixel were excluded if a flag was raised according to Table 4 (note that for geophysical products different terms are used by different authors and here the nomenclature is standardized for consistency throughout the paper, i.e. CHL for algal_2 and chl_conc; SPM for total_susp and tsm; aCDOM for yellow_subs and a_y_443). Only macro pixels with five or more non-flagged pixels were kept for further analysis and their pixel values were averaged (Kratzer and Vinterhav, 2010). The value of each macro pixel was assumed to represent the local conditions of the station cast for a given date. Due to the horizontal heterogeneity caused by the cyanobacterial blooms, a certain degree of variability within macro pixels is to be expected. Furthermore, coastal processes, fronts and natural gradients that may occur in the water body also add to this natural variability in the coastal zone. Nevertheless, after applying the exclusion criteria, the macro pixels were considered to have minimum horizontal heterogeneity for coastal conditions and obviously do not represent oligotrophic conditions. Therefore, the homogeneity test proposed by Bailey and Werdell (2006) to minimize the impact of geophysical variability within the macro pixels was modified to derive only those pixels after being filtered by the quality flags and minimum required pixels. The bias was calculated by using the standard deviation of the remaining "viable" pixels. This represents the minimum error that relates to the natural variability within the $3 \times 3$ pixel window.

Each processor may result in a different set of viable macro pixels. In order to ensure that all water quality estimates from the different processors compare the same pixels only those pixels that are common within a viable macro pixel for each processor were used to derive the macro pixel averaged value for comparison. For the radiometry only common macro pixels between all processors were used to assess the differences. For water products common macro pixels for each product among the pair of processors being compared are used for the analysis. This maximizes the number of viable macro pixels available for the differences estimates and ensures a fair comparison between the processors, i.e. the processors deal with the same pixels and observing conditions to derive the respective geophysical products.

For each processor the derived MERIS reflectance $\rho_{\mathrm{w}}(\lambda)$ from the ICOL-based processing scheme (SCEQ_L1N) and non-ICOL processing (SCEQ_X) were compared by calculating the percentage differences:

$\delta[\%]=\frac{\rho_{\mathrm{w}}(\lambda)_{\mathrm{ICOL}}-\rho_{\mathrm{w}}(\lambda)_{\mathrm{noICOL}}}{\rho_{\mathrm{w}}(\lambda)_{\mathrm{ICOL}}+\rho_{\mathrm{w}}(\lambda)_{\mathrm{noICOL}}} \times 200$

A transect along CI, CII and CIII stations (Fig. 1) was then used to extract the $\delta$ profile from FUB-derived MERIS reflectances, to show the effect of ICOL correction as a function of the geographic position. 
Table 4. Quality flags used for pixel exclusion criteria within a $3 \times 3$ pixel matrix.

\begin{tabular}{lll}
\hline \multirow{2}{*}{ L2 processor } & Geophysical product & Raised flags \\
\hline \multirow{2}{*}{ FUB } & algal_2, yellow_subs, total_susp & land, suspect, pcd_1_13, pcd_17 \\
\cline { 2 - 3 } & radiometry & land, suspect, pcd_1_13 \\
\cline { 2 - 3 } & algal_2 & LEVEL1b_masked, CHL_IN, CHL_OUT \\
\cline { 2 - 3 } & totlow_subs & LEVEL1b_masked, YEL_IN, YEL_OUT \\
\cline { 2 - 3 } & radiometry & LEVEL1b_masked, TSM_IN, TSM_OUT \\
\hline C2R & chl_conc, a_ys_443, tsm & case2_flags, agc_flags, 11_flags $>$ 2, \\
\cline { 2 - 3 } & radiometry & agc_flags, 11_flags $>2$ \\
\hline BOREAL & chl_conc, a_ys_443, tsm & case2_flags, agc_flags, 11_flags $>$ 2, \\
\cline { 2 - 3 } & radiometry & agc_flags, 11_flags $>2$ \\
\hline
\end{tabular}

\subsection{Comparison of MERIS-derived data products with in situ measurements}

For each processor the derived MERIS reflectance $\rho_{\mathrm{W}}(\lambda)$ from the ICOL-based processing scheme (SCEQ_L1N) and non-ICOL processing (SCEQ_X) were compared against the in situ TACCS data. Note that in this study the radiometric standard products of MEGS were considered (Antoine and Morel, 2011) and not the intermediate products of the neural nets that refer to the Case-2 Branch. Common macro pixels among the two processing schemes were selected and the sum of absolute differences against in situ data (SABS_D, Eq. 3) were calculated. These were then used to estimate the percentage of change between the two processing schemes $\left(\Delta_{\text {ICOL }}\right.$, Eq. 4$)$. Here, the SCEQ_X processing was used as a reference to evaluate the direction of change. A negative value of the $\Delta_{\text {ICOL }}$ indicates a reduction of SABS_D for the SCEQ_L1N processing.:

$\mathrm{SABS} \_\mathrm{D}=\sum_{i=1}^{n_{\text {casts }}}\left|\rho_{\mathrm{W}}(\lambda)_{i}^{\mathrm{MERIS}}-\rho_{\mathrm{w}}(\lambda)_{i}^{\mathrm{TACCS}}\right|$

$\Delta_{\mathrm{ICOL}}=$

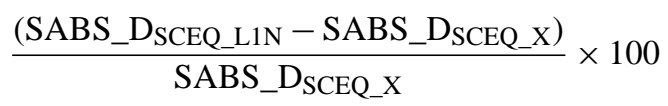

The validation was carried out over the data sets that had improved the MERIS reflectance for each processor. The ICOL-processed data sets (SCEQ_L1N) were the basis of the water product (CHL, SPM and aCDOM) validation, i.e. all level 2 products were smile corrected, equalized and a test on ICOL was performed. Based on the study of Kratzer and Vinterhav (2010) the ICOL-processed data were tested and worked as expected (i.e. reducing the land adjacency effects for pixels within $15-20 \mathrm{~km}$ to coast), therefore their basis for further data processing and statistical evidence was gathered to have substantially improved the MERIS reflectance retrieval for each processor. The data sets derived from SCEQ_L1N were then used to assess the differences in $\rho_{\mathrm{W}}(\lambda)$ retrieval amongst processors compared to in situ data.

Pair-wise comparison of the mean values of viable macro pixels to in situ data were then used for the analysis. Differences were quantified statistically by using the mean normalized bias (MNB, Eq. 5) which is an estimate of systematic errors assuming that the in situ data are a "true" values; the root mean square of relative differences $\left(\mathrm{RMS}_{\mathrm{RD}}, \mathrm{Eq} .6\right)$ that indicates dispersion in the retrieval:

$$
\begin{aligned}
& \mathrm{MNB}=\operatorname{mean}\left[\frac{y_{i}^{\text {MERIS }}-x_{i}^{\text {insitu }}}{x_{i}^{\text {insitu }}}\right] \times 100, \\
& \mathrm{RMS}_{\mathrm{RD}}=\operatorname{SD}\left[\frac{y_{i}^{\text {MERIS }}-x_{i}^{\text {insitu }}}{x_{i}^{\text {insitu }}}\right] \times 100,
\end{aligned}
$$

where $i=1 \ldots$ is the number of averaged macro pixels, and "mean" and "SD" refer to the calculations of the mean (Eq. 7) and standard deviation value (Eq. 8), respectively:

mean $=\bar{\chi}=\frac{1}{n} \sum_{i=1}^{n} \chi_{i}$

$\mathrm{SD}=\sqrt{\frac{1}{n-1} \sum_{i=1}^{n}\left(\chi_{i}-\bar{\chi}\right)^{2}}$

where $\chi$ is the variable of interest and $n$ the number of observations. 
Table 5. Range of concentrations of in situ water constituents.

\begin{tabular}{lllll}
\hline Water constituent & $\begin{array}{l}\text { In situ } \\
\text { mean [median] } \pm \mathrm{SD}\end{array}$ & $n$ & Min & Max \\
\hline$\left[\mathrm{CHL}, \mathrm{mg} \mathrm{m}^{-3}\right]$ & $3.98[2.68] \pm 3.60$ & 38 & 0.92 & 22.53 \\
\hline$\left[\mathrm{SPM}, \mathrm{g} \mathrm{m}^{-3}\right]$ & $1.46[1.34] \pm 0.69$ & 38 & 0.30 & 3.25 \\
\hline $\mathrm{aCDOM}_{440}, \mathrm{~m}^{-1}$ & $0.45[0.40] \pm 0.11$ & 17 & 0.36 & 0.82 \\
\hline
\end{tabular}

\section{Results}

The observed ranges of in situ concentrations of Chl $a$, SPM and aCDOM for the two sea-truthing campaigns are presented in Table 5. The median chlorophyll concentration measured in situ was about $2.7 \mathrm{mg} \mathrm{m}^{-3}$, the median SPM concentration was about $1.3 \mathrm{~g} \mathrm{~m}^{-3}$ and the median g440 (CDOM absorption at $440 \mathrm{~nm}$ ) was $0.4 \mathrm{~m}^{-1}$. The seatruthing data were found within the training ranges of the used level 2 processors (Tables 5 and 3) except for aCDOM during 2008. The in situ Chl $a$ and SPM had a positive correlation, $r=0.74$ (data from 2008 and 2010, Fig. 3). Low correlation values were found for aCDOM vs. Chl $a(r=0.02)$ and aCDOM vs. SPM ( $r=0.18)$ when the cast ID H4_6a is excluded as this single value was identified as outlier of normal conditions (data from 2010 only, as there were no aCDOM data for 2008).

The ranges of optical properties differed substantially for the two sea-truthing campaigns in 2008 and 2010. A higher range of concentrations for Chl $a$ and SPM were observed in 2008. A smaller range of Chl $a$ and SPM values were found for the sea-truthing data in 2010 (during full nitrogen treatment), whilst data from 2008 (no nitrogen treatment) generally had a greater range of values and were more variable. Station H5_3a in 2008 (Fig. 3) was found to be an outlier with the highest Chl $a$ and SPM values. This was during a strong cyanobacterial bloom in which usually the relationship between satellite data and truthing data breaks down because of strong patchiness of the water body and strong horizontal heterogeneity, making it difficult to compare the satellite retrievals to truthing data. Water transparency as measured by Secchi depth showed lesstransparent waters in 2008 with an average of $4.42 \pm 1.56 \mathrm{~m}$ compared to $6.45 \pm 1.65 \mathrm{~m}$ in 2010 . In 2008, a Secchi depth minimum value of $1.9 \mathrm{~m}$ was observed at station $\mathrm{H} 5$, with Secchi depths increasing towards the outer Himmerfjärden stations. The Secchi depth was not found to be above $3 \mathrm{~m}$ in 2008 for the inner stations H5 and H4; Station H3 showed a Secchi depth range of 2.9-3.5 m and for H2 Secchi depth ranged between 3.4 and 4.1 .

\subsection{MERIS reflectance evaluation}

For MEGS and FUB, the use of ICOL increased the number of viable macro pixels that previously had been flagged by

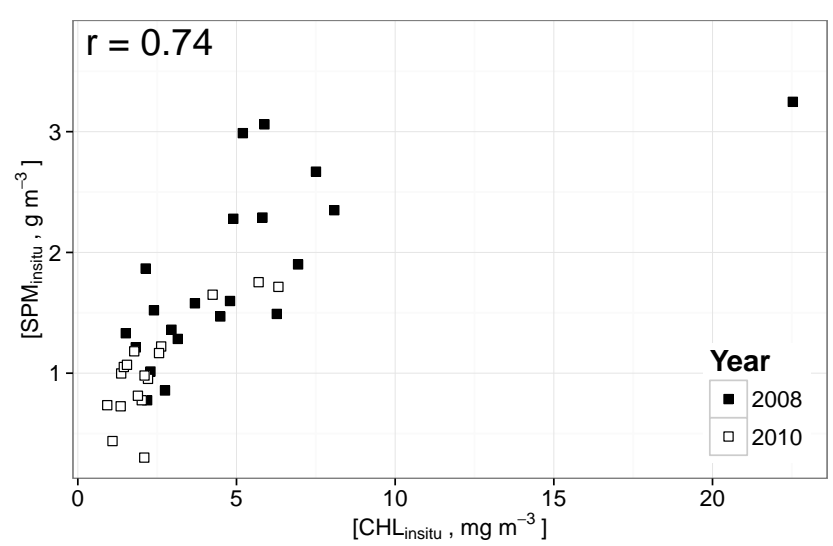

Figure 3. Correlation between [SPM] and [CHL]. The correlation coefficient, $r$, was calculated for both years.

the macro pixel quality and exclusion criteria applied. Radiometric products derived after ICOL processing reduced the reflectance for previous overestimations and also reduced underestimations, especially in the blue-green region of the spectrum. The result is less flagging by each processor by correcting for atmospheric effects (in this case atmospheric scattering or stray light from land) prior to atmospheric correction performed by each processor. An example of the spatial distribution of the percentage difference on MERIS reflectance (image from 28 July 2008, during a cyanobacterial bloom) using FUB, when ICOL and no ICOL processing was applied ( $\delta[\%]$, Eq. 2$)$ is shown for selected wavelengths, $443 \mathrm{~nm}$ (Fig. 4c) and $708 \mathrm{~nm}$ (Fig. 4e). The extracted profile of $\delta[\%]$ along a transect, from coast to open sea waters (representing the CI, CII, CIII stations), is given for all the available FUB bands and for the selected wavelengths (443 and $708 \mathrm{~nm}$ ), see Fig. 4b, d, f, respectively.

The number of available macro pixels for the processor MEGS without using ICOL was 17, and after ICOL there were 24 macro pixels, i.e. an increase of $41 \%$ of viable pixels. The number of available macro pixels for FUB after ICOL processing were 19 , an increase of $35 \%$. For the locations $\mathrm{H} 2$ and $\mathrm{H} 3$, only FUB could retrieve the reflectance reliably. The number of available macro pixels for both $\mathrm{C} 2 \mathrm{R}$ and BOREAL was 27 with no change on the available pixels after ICOL processing. Based on these results, the ICOL-based data sets were used for the following comparison of level 2 products derived from all processors. Common macro pixels used to evaluate the retrieval of $\rho_{\mathrm{W}}(\lambda)$ resulted in 16 common macro pixels among the four processors after macro pixel quality control and exclusion criteria using the SCEQ_L1N data sets.

An example of the spatial distribution of the absolute value of $\delta$ and profile plots of $\delta$ values by using FUB, when ICOL and no ICOL processing has been applied, is shown in Fig. 4. The scene was registered on 28 July 2008 during a cyanobacterial bloom (Fig. 4a). The results show the typical 


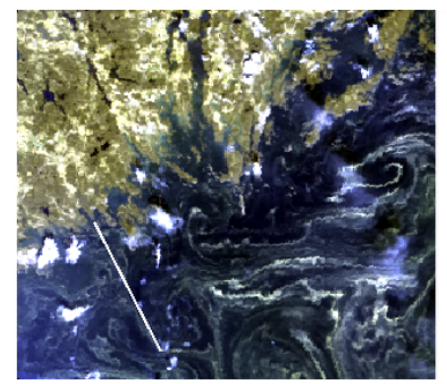

(a)

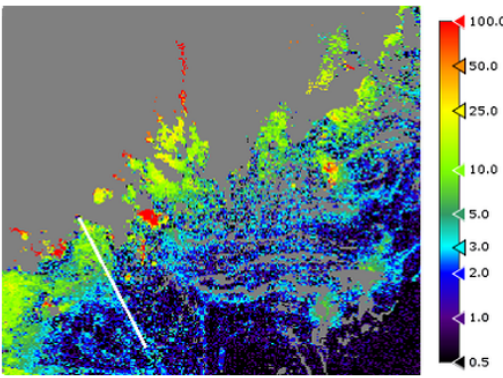

(c)

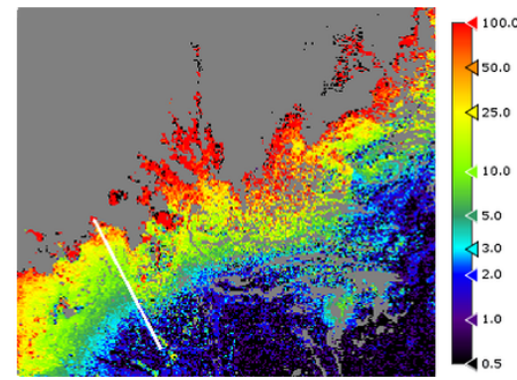

(e)

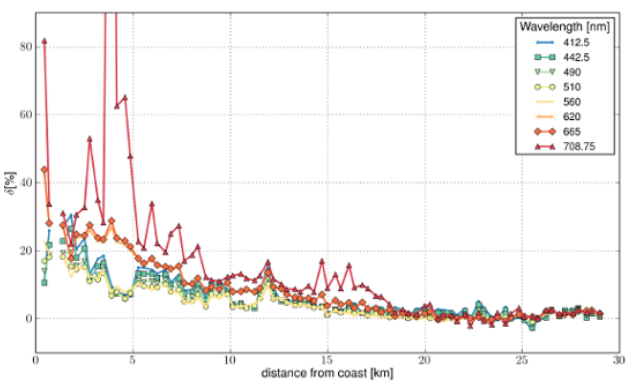

(b)

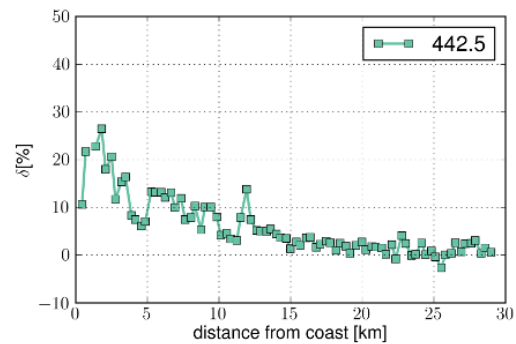

(d)

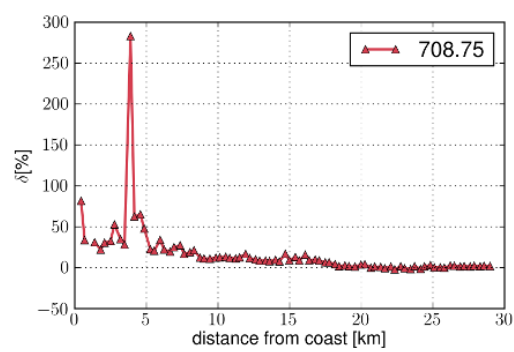

(f)

Figure 4. Example of spatial distribution and profile plots of the percentage difference in MERIS reflectance using FUB, when ICOL and no ICOL processing has been applied. (a) RGB composite; (b) reflectances in all channels show a logarithmic decline as expected; (c and d) percentage difference in the blue channel; (e and f) percentage difference in the NIR channel at $709 \mathrm{~nm}$. The peak at about $4 \mathrm{~km}$ distance from land in the NIR is most likely caused by surface scum.

exponential decay of adjacency corrections when moving towards the open sea (Fig. 4b). The ICOL correction is notable up to $20 \mathrm{~km}$ (Fig. $4 \mathrm{~b}, \mathrm{c}, \mathrm{d}$, e, f), with lower $\delta$ towards the blue wavelengths. Higher $\delta$ values $(>10 \%)$ can be observed for the first $5 \mathrm{~km}$ in all bands. Beyond $15 \mathrm{~km}$ offshore $\delta$ are below $8 \%$ for all selected bands, except for $708 \mathrm{~nm}$. The red band at $708 \mathrm{~nm}$, shows the highest $\delta$ with range values $10-300 \%$ within the first $10 \mathrm{~km}$ (Fig. 4b, f). After $10 \mathrm{~km}$ the differences found in this wavelength are similar to the other bands (Fig. 4b, d, f).

In general, FUB and MEGS estimates showed bias, thus an underestimation of $\rho_{\mathrm{w}}(\lambda)$ showed up in all bands compared to sea-truthing data (Table 6). The FUB processor underestimated $\rho_{\mathrm{w}}(\lambda)$ by between $22 \%$ and $32 \%$, while MEGS underestimates by $7-16 \%$ in the spectral bands above $443 \mathrm{~nm}$. For MEGS $\rho_{\mathrm{w}}(\lambda)$ estimates the highest underestimations $(35 \%)$ were found at $413 \mathrm{~nm}$. On the other hand, an overestimation was found for $\mathrm{C} 2 \mathrm{R}$ for the blue spectral bands, while the lowest bias occurs for the green spectral bands at 510 and $560 \mathrm{~nm}$ (1.1 and $8 \%$, respectively) for this processor. It may be pointed out that the highest uncertainty in the TACCS estimates occurs in the red channels (Zibordi et al., 2012), but the satellite retrieval amongst processors was most consistent in the red.

The $\rho_{\mathrm{w}}(\lambda)$ estimates showed relatively low correlation in the blue bands 413 and $443 \mathrm{~nm}$ for all processors (Table 6). The correlation coefficient of $r=0.11$ for FUB at $413 \mathrm{~nm}$ was the lowest amongst all processors. The best correlation with in situ values, with $r$ values above 0.84 for all processors and as high as 0.91 for MEGS, was found for the $560 \mathrm{~nm}$ wavelength (Fig. 5, Table 6). For $\rho_{\mathrm{w}}(\lambda=560)$ an underestimation and increase of variability higher than 0.015 was observed. 
Table 6. Summary of error analysis for $\rho(\lambda)$ against sea-truthing data using common macro pixels $(n=16)$. MERIS data set processing chain SCEQ_L1N-Smile Corrected and Equalized with ICOL.

\begin{tabular}{lrrrr}
\hline Processor & $\lambda$ & MNB [\%] & RMS $_{\mathrm{RD}}[\%]$ & $r$ \\
\hline FUB & 413 & -23.38 & 35.91 & 0.11 \\
& 443 & -26.86 & 26.66 & 0.35 \\
& 490 & -22.18 & 18.47 & 0.66 \\
& 510 & -26.33 & 13.82 & 0.77 \\
& 560 & -29.28 & 11.76 & 0.84 \\
& 620 & -29.70 & 16.59 & 0.75 \\
& 665 & -32.58 & 16.19 & 0.77 \\
\hline MEGS & 413 & -35.23 & 65.87 & 0.33 \\
& 443 & -18.91 & 41.47 & 0.47 \\
& 490 & -12.67 & 21.52 & 0.77 \\
& 510 & -15.71 & 17.25 & 0.82 \\
& 560 & -12.84 & 13.39 & 0.91 \\
& 620 & -6.65 & 17.72 & 0.84 \\
& 665 & -10.04 & 19.47 & 0.78 \\
\hline C2R & 413 & 28.10 & 81.60 & 0.52 \\
& 443 & 20.38 & 61.70 & 0.56 \\
& 490 & 17.64 & 43.92 & 0.69 \\
& 510 & -1.12 & 28.28 & 0.78 \\
& 560 & -8.01 & 17.99 & 0.87 \\
& 620 & 4.55 & 20.46 & 0.81 \\
& 665 & -12.26 & 19.58 & 0.77 \\
\hline
\end{tabular}

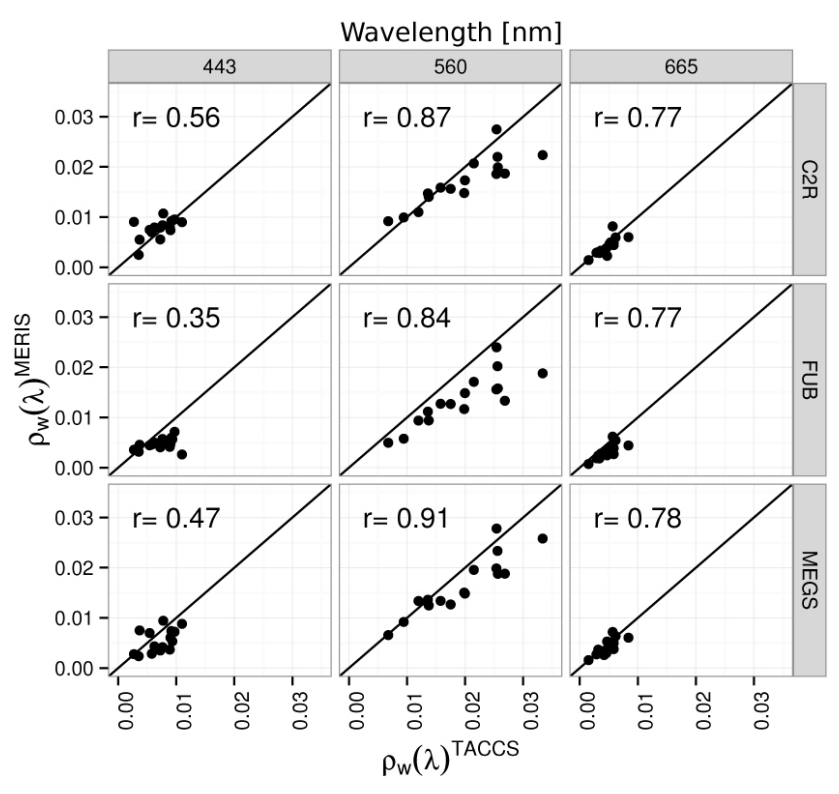

Figure 5. Correlation between MERIS and TACCS $\rho_{\mathrm{w}}(\lambda)$ for each processor using common macro pixels. The solid black line represents the $1: 1$ line. The correlation coefficient is given by $r$. The figure columns represent selected wavelengths: blue $(443 \mathrm{~nm})$, green $(560 \mathrm{~nm})$ and red (665). The C2R and BOREAL had the same results, so only the $\mathrm{C} 2 \mathrm{R}$ is presented here.
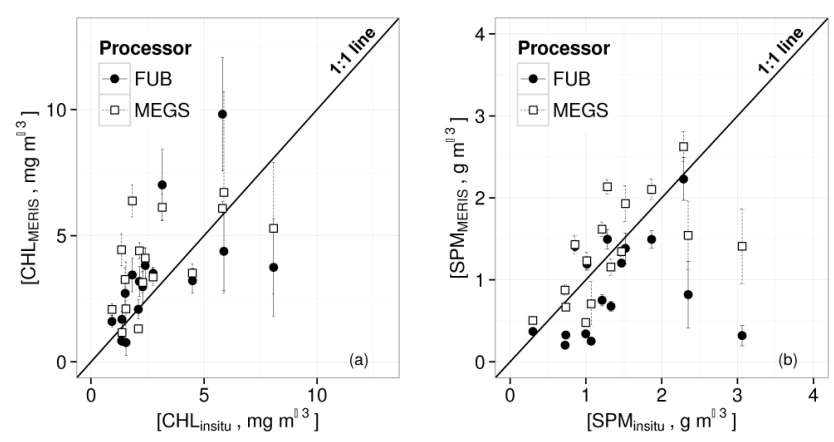

Figure 6. Correlation for the pairwise [CHL] and [SPM] comparison between FUB vs. MEGS (a, b) compared to sea-truthing measurements. Data correspond to common macro pixels. The error bars are the standard deviation of the macro pixel. The solid black line represents the $1: 1$ line.

\subsection{CHL evaluation}

In general, all processors overestimated the CHL concentration. FUB was found to have the lowest bias and dispersion (Table 7). FUB showed an overestimation of chlorophyll of about $18-27 \%$, depending on the compared pairs after macro pixel exclusion criteria. MEGS showed an overestimation of 57-62\%. The dispersion of FUB were consistent among pairs with $\mathrm{RMS}_{\mathrm{RD}}$ values not higher than $55 \%$, while $\mathrm{C} 2 \mathrm{R}$ dispersion varied among pairs and was above $104 \%$. MEGS dispersion was intermediate between 77 and $87 \%$. BOREAL presented the highest bias and dispersion in all pairs (Table 7). FUB showed less variability at lower CHL concentrations (e.g. $<4 \mathrm{mg} \mathrm{m}^{-3}$, Fig. 6a) than C2R and MEGS.

\subsection{SPM evaluation}

The MEGS processor was the most accurate in retrieving SPM, while systematic overestimations were obtained with the MEGS, C2R and BOREAL processors. Only with the FUB processor were the SPM loads underestimated in all compared pairs (Table 8). When compared to FUB a MNB of only about $8 \%$ was obtained by MEGS, whereas an underestimation of $28 \%$ was found for the FUB processor. The C2R retrievals were also satisfying when the processor was compared (pairwise with FUB and MEGS) to in situ measurements (5.5 and $25.21 \%$, respectively). Data scatter (noise) expressed by the RMS $\mathrm{RD}_{\mathrm{RD}}$ was mainly found in the range of $40-50 \%$ among all processors, with the exception for BOREAL. The BOREAL estimates showed the highest noise with values above $60 \%$.

The retrieved SPM concentrations by MEGS were associated with significant noise, while small bias (Table 8) was obtained when compared to FUB (Fig. 6b). The C2R and MEGS estimates are relatively close to the $1: 1$ line, covering a wider range of in situ concentrations. The MEGS retrievals have the lowest bias and noise (Table 8). 
Table 7. Summary of error analysis for [CHL] compared to seatruthing using common macro pixels by each pair of processors. MERIS data set processing chain SCEQ_L1N-Smile Corrected and Equalized with ICOL.

\begin{tabular}{llrrr}
\hline Pair & Processor & $n$ & MNB [\%] & RMS $_{\mathrm{RD}}[\%]$ \\
\hline FUB_MEGS & FUB & 16 & 26.53 & 54.46 \\
& MEGS & & 62.23 & 86.93 \\
\hline C2R_FUB & C2R & 21 & 73.59 & 119.65 \\
& FUB & & 17.77 & 52.28 \\
\hline C2R_MEGS & C2R & 21 & 82.83 & 109.91 \\
& MEGS & & 56.76 & 77.38 \\
\hline BOREAL_MEGS & BOREAL & 11 & 241.39 & 169.70 \\
& MEGS & & 96.45 & 81.51 \\
\hline BOREAL_FUB & BOREAL & 11 & 266.79 & 211.02 \\
& FUB & & 45.79 & 53.48 \\
\hline BOREAL_C2R & BOREAL & 14 & 239.22 & 193.90 \\
& C2R & & 110.14 & 104.86 \\
\hline
\end{tabular}

\section{4 aCDOM evaluation}

All processors underestimated aCDOM (Table 9). MEGS and $\mathrm{C} 2 \mathrm{R}$ were not able to resolve the in situ aCDOM distribution as all the retrieved macro pixels estimated similar aCDOM values (Fig. 7). FUB was able to resolve changes in aCDOM, albeit with a systematic underestimation when compared to in situ values. Figure 8 shows the regression equation obtained between FUB retrieved and in situ measured aCDOM that can be used as local correction factor in order to improve the aCDOM retrieval. However, it must be noted that this regression will only be valid for the range of concentrations investigated here.

The results confirm the challenges to estimate aCDOM in the Baltic Sea accurately when a limited data set is applied to the present processors. In this study, 17 in situ aCDOM samples from 2010 were available for satellite validation. As mentioned before, the aCDOM field measurements for 2008 were not available. After applying the macro pixel quality control and exclusion criteria during the pairwise combination, a reduced number of macro pixels were available to perform the comparisons with in situ data. The pairwise combination of C2R vs. FUB showed the maximum available pixels, with only seven macro pixels left. The quality control of BOREAL when common macro pixels are used in the pairwise comparison left only one or two viable pixels to make such comparisons, making it impossible to evaluate.

\subsection{CHL and SPM evaluation by year}

Using all available individual macro pixels for FUB $(n=26$, 16 and 10 observations in 2008 2010, respectively), the CHL retrievals (Table 10) showed lower bias for 2008 than 2010 (MNB $=16$ and $24 \%$, respectively). The dispersion obtained
Table 8. Summary of error analysis for [SPM] compared to seatruthing data using common macro pixels by each pair of processors. MERIS data set processing chain SCEQ_L1N-Smile Corrected and Equalized with ICOL.

\begin{tabular}{llrrr}
\hline Pair & Processor & $n$ & MNB [\%] & RMS $_{\text {RD }}[\%]$ \\
\hline FUB_MEGS & FUB & 16 & -27.46 & 43.66 \\
& MEGS & & 7.85 & 39.87 \\
\hline C2R_FUB & C2R & 21 & 5.50 & 50.56 \\
& FUB & & -37.05 & 42.46 \\
\hline C2R_MEGS & C2R & 21 & 25.21 & 47.81 \\
& MEGS & & 16.16 & 42.42 \\
\hline BOREAL_MEGS & BOREAL & \multirow{2}{*}{11} & 76.95 & 61.82 \\
& MEGS & & 35.70 & 33.53 \\
\hline BOREAL_FUB & BOREAL & \multirow{2}{*}{11} & 47.52 & 78.52 \\
& FUB & & -25.90 & 42.64 \\
\hline BOREAL_C2R & BOREAL & 14 & 54.87 & 73.11 \\
& C2R & & 32.54 & 47.71 \\
\hline
\end{tabular}

Table 9. Summary of error analysis for aCDOM compared to seatruthing data using common macro pixels by each pair of processors. MERIS data set processing chain SCEQ_L1N-Smile Corrected and Equalized with ICOL.

\begin{tabular}{llrrr}
\hline Pair & Processor & $n$ & MNB [\%] & RMS $_{\text {RD }}[\%]$ \\
\hline \multirow{2}{*}{ FUB_MEGS } & FUB & 5 & -68.35 & 7.04 \\
& MEGS & & -89.89 & 2.56 \\
\hline \multirow{2}{*}{ C2R_FUB } & C2R & 7 & -88.71 & 2.68 \\
& FUB & & -68.64 & 5.16 \\
\hline C2R_MEGS & C2R & \multirow{2}{*}{6} & -89.11 & 2.38 \\
& MEGS & & -90.08 & 2.34 \\
\hline
\end{tabular}

with the FUB processor was higher for 2010 than 2008 (108 and $61 \%$, respectively). Biases of $57 \%$ and $56 \%$ were obtained with the MEGS processor for 2008 and 2010, respectively. Using MEGS, the total number of retrieved macro pixels for CHL was 21 (15 observations in 2008 and 6 observations in 2010). Data dispersion was above $69 \%$ for both years $\left(\mathrm{RMS}_{\mathrm{RD}} 70 \%\right.$ and $102 \%, 2008$ and 2010 respectively). Suspended particulate matter showed lower bias and data dispersion in 2010 than in $2008\left(\mathrm{MNB}=-1 \%, \mathrm{RMS}_{\mathrm{RD}}=43 \%\right)$ using MEGS (Table 10). FUB underestimated SPM in both years by $47 \%$. The $\mathrm{C} 2 \mathrm{R}$ processor was the only processor retrieving the same number of macro pixels regardless of the water product $(n=27)$. FUB and MEGS retrieved fewer individual macro pixels for SPM than for CHL (macro pixel ratio SPM/CHL 19/26 FUB and 15/21 for MEGS).

In order to obtain a fair comparison of the performance of FUB and MEGS by using the individual macro pixel a subset of the macro pixel data set was used. Station H5 was removed from the FUB data set, as it drives the correlation of 


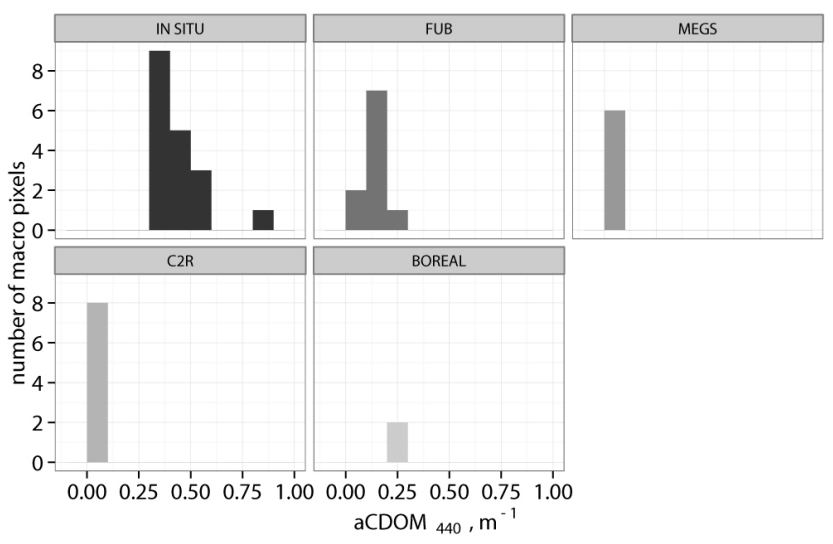

Figure 7. Histogram showing the distribution of macro pixel CDOM absorption $\left[\mathrm{m}^{-1}\right]$ for each level 2 processors.

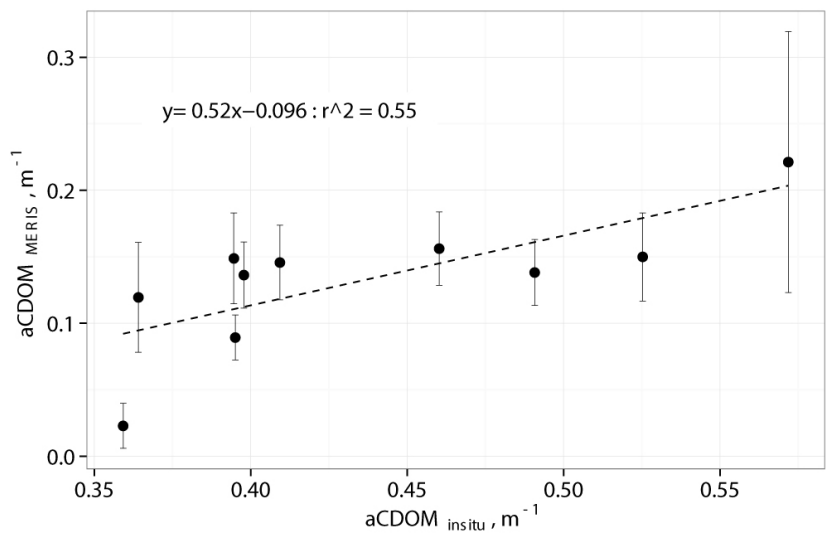

Figure 8. Regression of aCDOM derived from FUB compared to sea-truthing data.

CHL vs. sea-truthing for 2008 and may add a clear bias to the results as this station was not retrieved by MEGS after the macro pixel quality and exclusion criteria were applied for the same year. Furthermore, the open-sea stations CI, CII and CIII, which are in a different sub-catchment and represent a different water body than the stations within and close to the Himmerfjärden bay, were therefore also removed from the comparison.

Higher ranges of CHL values and variability was observed during 2008 than in 2010, for both processors (Table 11). MEGS had lower bias in 2008 (MNB = $23.1 \%)$ and reduced dispersion $\left(\mathrm{RMS}_{\mathrm{RD}}=36.9\right)$ than FUB $\left(\mathrm{MNB}=28.5 ; \mathrm{RMS}_{\mathrm{RD}}=37.1\right)$. However, in 2010 the opposite performance occurred for MEGS $(\mathrm{MNB}=55.8$; $\left.\mathrm{RMS}_{\mathrm{RD}}=102.0\right)$, FUB being more accurate $(\mathrm{MNB}=24.1$; $\mathrm{RMS}_{\mathrm{RD}}=108.2$ ).

Suspended particulate matter bias and dispersion in FUB and MEGS remained without change after using the subset of individual macro pixels. The inner stations within Himmerfjärden show a higher discrepancy to the sea-truthing data in 2008 for both processors.
Table 10. Summary of error analysis for [CHL] and [SPM] by year compared to sea-truthing data using individual best macro pixels. MERIS data set processing chain SCEQ_L1N-Smile Corrected and Equalized with ICOL.

\begin{tabular}{|c|c|c|c|c|c|}
\hline Processor & Water product & Year & $n$ & MNB [\%] & $\mathrm{RMS}_{\mathrm{RD}}[\%]$ \\
\hline \multirow[t]{6}{*}{ FUB } & [CHL] & 2008 & 16 & 15.5 & 60.9 \\
\hline & & 2010 & 10 & 24.1 & 108.2 \\
\hline & & both & 26 & 18.8 & 80.4 \\
\hline & [SPM] & 2008 & 9 & -47.0 & 55.8 \\
\hline & & 2010 & 10 & -40.2 & 50.4 \\
\hline & & both & 19 & -43.4 & 51.6 \\
\hline \multirow[t]{6}{*}{ MEGS } & [CHL] & 2008 & 15 & 56.6 & 70.0 \\
\hline & & 2010 & 6 & 55.8 & 102.0 \\
\hline & & both & 21 & 56.4 & 77.6 \\
\hline & [SPM] & 2008 & 9 & 22.5 & 51.7 \\
\hline & & 2010 & 6 & -0.9 & 42.3 \\
\hline & & both & 15 & 13.1 & 48.0 \\
\hline \multirow[t]{6}{*}{$\mathrm{C} 2 \mathrm{R}$} & [CHL] & 2008 & 19 & 58.9 & 95.5 \\
\hline & & 2010 & 8 & 88.9 & 134.3 \\
\hline & & both & 27 & 67.7 & 106.6 \\
\hline & [SPM] & 2008 & 19 & 19.6 & 55.4 \\
\hline & & 2010 & 8 & 3.8 & 46.6 \\
\hline & & both & 27 & 14.9 & 52.6 \\
\hline
\end{tabular}

Nevertheless, caution is advised in the interpretation of results using individual macro pixels because they cannot be directly compared between FUB and MEGS; they represent their individual best, and they may not share the same observed macro pixels (as in the previous sections), thus they are likely to show discrepancies because the same pixels may not be compared. However, this comparison highlights the processor individual performance and its potential limitations within Himmerfjärden and adjacent areas.

\section{Discussion}

The results from the processors have shown less accurate $\rho_{\mathrm{w}}(\lambda)$ retrievals in the blue spectral region and better agreement in the green-red spectral region, similar to other optically complex coastal water bodies (Park et al., 2004). Relatively low $\rho_{\mathrm{w}}(\lambda)$ in situ values in the blue bands 413 and 443 can be expected as the optical properties of the Baltic Sea are dominated by aCDOM (Schwarz et al., 2002; Darecki and Stramski, 2004; Reinart and Kutser, 2006) and SPM is low (Park et al., 2004).

FUB has a rather consistent off-set over the wavelengths of the reflectance spectrum analysed (Table 6), and has therefore the most consistent spectral shape, i.e. the MNB do not change as drastically as for the other processors. MEGS has shown lower bias than FUB (Table 6) for all wavelengths except $413 \mathrm{~nm}$ when using the standard MERIS reflectance considering the Case- 1 water branch. This is notable for MEGS over optically complex waters, and suggests 
Table 11. Summary of error analysis for [CHL] and [SPM] by year compared to a subset of sea-truthing data using individual best macro pixels. MERIS data set processing chain SCEQ_L1N-Smile Corrected and Equalized with ICOL.

\begin{tabular}{lllrrr}
\hline Processor & Water product & Year & $n$ & MNB [\%] & RMS $_{\mathrm{RD}}[\%]$ \\
\hline FUB & [CHL] & 2008 & 9 & -28.5 & 37.1 \\
& & 2010 & 10 & 24.1 & 108.2 \\
& & both & 19 & -0.8 & 84.8 \\
\cline { 3 - 6 } & \multirow{2}{*}{ SPM] } & 2008 & 9 & -47.0 & 55.8 \\
& & 2010 & 10 & -40.2 & 50.4 \\
& & both & 19 & -43.4 & 51.6 \\
\hline \multirow{2}{*}{ MEGS } & {$[\mathrm{CHL}]$} & 2008 & 9 & 23.1 & 36.9 \\
& & 2010 & 6 & 55.8 & 102.0 \\
& & both & 15 & 36.2 & 69.0 \\
\cline { 3 - 6 } & {$[\mathrm{SPM}]$} & 2008 & 9 & 22.5 & 51.7 \\
& & 2010 & 6 & -0.9 & 42.3 \\
& & both & 15 & 13.1 & 48.0 \\
\hline
\end{tabular}

a further improvement of the standard radiometric products when ICOL is applied. However, Zibordi et al. (2013) recommended that the resulting MERIS reflectances that result from the Case- 2 water branch processing should be added to the MERIS standard data products. This would facilitate the assessment especially in relation with the creation of climate data records.

Surface accumulations of Cyanobacteria may increase the percentage difference of ICOL and no ICOL-based data sets. The observed higher $\delta$ values at $708 \mathrm{~nm}$ (Fig. 4b, d) coincide with visible fronts caused by Cyanobacteria (Fig. 4a). These high peaks at $708 \mathrm{~nm}$ are also coincident with a $\delta$ decrease observed in the blue-green bands (Fig. 4b, d), that suggest strong chlorophyll absorption (Fig. 4d). This result may be used to the development of a cyanobacterial surface accumulation flags which requires further research.

Differences in CHL and SPM retrievals by MEGS and $\mathrm{C} 2 \mathrm{R}$ were observed. However, the MEGS Case-2 branch and the $\mathrm{C} 2 \mathrm{R}$ share not only the same architecture, but the water and atmospheric neural networks used in their biooptical model are also the same (at least for processors versions used here for MEGS 8.1 and C2R 1.5.3, C. Mazeran, personal communication, 2013). Therefore, these differences may arise in the implementation of pre-corrections of the top of atmosphere (TOA) signal (e.g. smile and gaseous corrections) and in the use of predefined physical constants (i.e. the solar flux at theoretical wavelengths) that may scale up in the level 2 water products.

At lower in situ chlorophyll concentrations (mainly $<2.5 \mathrm{mg} \mathrm{m}^{-3}$, Fig. 6) relatively large data dispersion dominates the retrievals. FUB is more stable and accurate especially in the open Baltic Sea, while MEGS and C2R showed greater variability. This higher variability is expressed in C2R and MEGS as an overestimation with higher noise in the retrieval which is in agreement with the findings of Zibordi et al. (2013) for the Baltic Sea. Low performance of the neural network processors occurs for decreasing pigment concentrations in waters dominated by CDOM absorption, as aCDOM and SPM become the dominate optical signals (Doerffer and Schiller, 2007). At relatively high aCDOM, these differences may also be linked to the relatively small ranges of in situ SPM and $\mathrm{Chl} a$ concentrations in comparison to the higher range of the processors (Table 5). As a consequence, in MEGS and C2R, low chlorophyll concentrations may be overestimated, while higher concentrations may not be overestimated. This may lead to a reduced difference between higher and lower pigment concentrations. An expression of this effect may be a reduced contrast of the image over the same range of values in comparison to FUB.

Furthermore, Heim et al. (2008) mentioned that by using the $\mathrm{C} 2 \mathrm{R}$ in optically complex waters the main attribution of the total absorption goes towards the pigment absorption, leading to an overestimation of CHL at low chlorophyll concentrations and hence an underestimation of aCDOM. This is consistent with findings of Attila et al. (2013) and González Vilas et al. (2011). Attila et al. (2013) have also suggested that $\mathrm{C} 2 \mathrm{R}$ retrievals in the Baltic Sea can be improved by modifying the mean conversion factors of the specific inherent optical properties, SIOPs (i.e. the chlorophyll conversion factor and exponent), used to derive the chlorophyll concentration from the absorption of phytoplankton pigments by using appropriate regional factors.

The concentration of suspended particulate matter was more accurate with MEGS. Zibordi et al. (2013) reported a similar indication of accurate retrieval of SPM for MEGS across various European seas. In the presented study here, FUB showed lower accuracies for SPM retrievals than MEGS and C2R. These underestimations occurred mostly within Himmerfjärden, for the stations $\mathrm{H} 3, \mathrm{H} 4$ and $\mathrm{H} 2$ of the 18 July 2008 and 15 July 2008 data sets. During 2008, the inner stations of Himmerfjärden were highly influenced by the release of nitrogen from the Himmerfjärden sewage treatment plant. Higher SPM and aCDOM values observed in 2010 at the station H4 (cast ID: H4_6a, Table 1). This suggests that the location of $\mathrm{H} 4$ may optically be strongly influenced by the effluent outflow of the Himmerfjärden sewage treatment plant.

Another potential cause of FUB SPM underestimations for stations not affected by atmospheric correction problems may be linked to the relatively small ranges of in situ SPM concentrations in comparison to the much higher range of the processor, combined with relatively high aCDOM in Baltic Sea waters. The underestimation of $\rho_{\mathrm{w}}(\lambda)$ in the green band $(560 \mathrm{~nm})$ combined with a higher variability above $>0.15$ seemed to affect FUB retrieval. The spectral band at $560 \mathrm{~nm}$ is related to the type and concentration of particulate material present in the water column which contributes to the absorption and backscattering of light. A highly variable distribution of particles affects the $\rho_{\mathrm{w}}(\lambda)$ in the coastal zone 
(Stramski et al., 2004; Roesler and Boss, 2008). As the particle concentrations increase (including phytoplankton cells, organic particles, and detrital particulates) the backscattering and thus reflectance increases, but parallel to this, the absorption may increase due to high aCDOM, hence reducing the reflectance. Different phytoplankton communities may also affect the size and shape of the backscattering signal. Cyanobacteria have highly reflective gas vacuoles for regulating their buoyancy. Furthermore, they form dense aggregations having a non-uniform distribution vertically and horizontally affecting both the absorption and scattering ratios (Kutser, 2004).

The individual macro pixel evaluation for FUB and MEGS showed some limitations in the performance of both processors. The truthing data showed that within Himmerfjärden Secchi depth was reduced and highly variable in 2008. Higher dissolved and suspended matter may have been released into the bay during lack of nitrogen treatment inducing the stimulation of primary production by increased release of the nutrients from Himmerfjärden sewage plant. Water transparency was therefore decreased. CDOM absorption may also have been increased beyond the limit of the aCDOM range for FUB as indicated by the high absorption measured by the AC 9 and also by increased $K_{d}(490)$ values which are highly correlated to aCDOM. Vaičiūtè et al. (2012) found Secchi depth strongly correlated to aCDOM and SPM, and being the most influential factors explaining the discrepancies between MERIS-derived products and in situ data for Lithuanian coastal waters. High values of organic SPM during summer indicate the occurrence of cyanobacterial blooms, which may also add to the decreased light transparency indicated by lower Secchi depths. In Baltic Sea waters, it is usually aCDOM that is the dominant optical component influencing Secchi depth, but it is known to be less variable over space and time than SPM (Kratzer and Tett, 2009), SPM contributing more to the variability in Secchi depth.

FUB showed the highest discrepancies for the stations where Secchi values $<3.5 \mathrm{~m}$ were measured for both CHL and SPM. Dispersion seems to dominate the retrieval of FUB CHL within Himmerfärden bay (Table 11). MEGS performed better in 2008 for CHL (i.e. at high chlorophyll ranges) and it seems to be able to retrieve higher CHL concentrations with high attenuation background. Although the sample size is very small, these results are consistent with the findings of Vaičiūtė et al. (2012) for the offshore area and in the plume area of the Curonian lagoon where even more turbid waters and higher aCDOM can be found. The authors found that the MERIS standard processor provided the best fit when compared to sea-truthing data. However, FUB was shown to flag less data than the standard processor (only $10 \%$ of data were removed by FUB flags, whereas the standard processor removed $60 \%$ of the matchups). In this study, FUB also flagged less data than MEGS as can be seen from the number of observations in the subset data set for 2010 (FUB $n=10$, MEGS $n=6$, Table 11). FUB seems to have better agreement with sea-truthing data at low CHL values (e.g. $<4 \mathrm{mg} \mathrm{m}^{-3}$ ) and with lower variability for open-sea stations. FUB SPM retrievals were mostly underestimated (Table 11), which may be related primarily to atmospheric variability and clouds. The training data set in FUB may not be representative for the natural patterns of SPM occurring in the region of interest, as the data set used for training the neural nets was from the COASTLOOC project (Babin, 2000) representing more frequently waters with higher SPM. Furthermore, the inner stations remain underestimated for SPM and CHL using FUB, which may also suggest atmospheric correction failure (Cristina et al., 2009; Kratzer et al., 2008) not detected by the water flags in FUB, combined with adjacency effects that may limit the accuracy of SPM and CHL retrieval within Himmerfjärden. MEGS was able to retrieve SPM at lower concentrations than FUB for 2010, but MEGS may also be strongly affected by failure of atmospheric and/or adjacency correction for the inner stations in the bay (Table 11).

Further, the study of Sørensen et al. (2007) showed uncertainty of 5-20\% for deriving CHL with the spectrophotometric method in an international intercomparison between laboratories. Taking this into account, the overall accuracies obtained in this study using FUB and MEGS for retrieving CHL from natural phytoplankton in coastal waters can be considered satisfying with regards to bias. In the pairwise retrieval, chlorophyll was retrieved best using FUB with an overestimation between 18 and $26.5 \%$ (MNB) and with a MNB of $-29 \%$ (2008) and $24 \%$ (2010) in the individual FUB-seatruthing comparison, which means that CHL can be derived within $30 \%$ bias. The error of measuring SPM for the seatruthing method used here is about $10 \%$ in situ, and the pairwise retrieval showed MNB errors of 8-16\% for MEGS and -28 to -37 for FUB in this study. However, the previous study by Kratzer and Vinterhav (2010) showed better SPM retrieval for FUB using MERIS data from the 2nd reprocessing with MNB $-4 \%$ in the open sea, and $-15 \%$ inside Himmerfjärden. For MEGS MNB was $-22 \%$ in the open sea, and $-12 \%$ inside Himmerfjärden.

\section{Conclusions}

We have presented a processing chain for MERIS fullresolution products which is dedicated to CDOM-rich waters. Including the ICOL adjacency correction in the chain improves the accuracy of the generated marine reflectances as well as the derived water products when compared to seatruthing data. Therefore it is recommended to include ICOL in coastal Baltic Sea Waters.

Evidence was found that cyanobacterial surface accumulation flags can be developed by using the high readings at $709 \mathrm{~nm}$ (red edge) at the same time as a dip in the blue reflectance (high chlorophyll); where the difference in the spectral signatures may indicate surface accumulations 
which become evident when deriving the percentage difference between ICOL and non-ICOL processed data sets (Fig. 4).

Overall, all investigated processors overestimate CHL values. Suspended particulate matter is retrieved better by all processors than the other water constituents. In the inversion process aCDOM strongly competes with CHL absorption causing aCDOM to be underestimated, and this may also affect CHL and SPM retrievals.

FUB is more accurate in the retrieval of CHL. In MEGS data dispersion dominates the retrievals at low chlorophyll $<2.5 \mathrm{mg} \mathrm{m}^{-3}$.

MEGS is more accurate for SPM retrieval. FUB showed the highest discrepancies in SPM concentrations for stations with high atmospheric variability and where high Secchi depth $<3.5 \mathrm{~m}$ was measured.

The choice of whether to use FUB or MEGS for retrieval of SPM in a given area of the Baltic Sea must be assessed against local conditions and ranges of optical components.
For future algorithm development in waters affected by high CDOM absorption it is therefore recommended to decouple the aCDOM retrieval from the retrieval of the CHL absorption at $443 \mathrm{~nm}$ (where high absorption of both $\mathrm{aC}$ DOM and CHL coincide), and instead use other spectral features of phytoplankton pigments in the longer wavelengths for chlorophyll retrieval, e.g. the chlorophyll peak in the red at about $665 \mathrm{~nm}$.

Furthermore, the application of regional mean conversion factors SIOPs is recommended for potential improvements of MEGS or C2R before suggesting a processing change in the operational system. Although MEGS has already shown potential to be used as operational processor in the Himmerfjärden bay and adjacent areas, it requires further improvement of the atmospheric correction for the blue bands and better definition at relatively low chlorophyll concentrations in the presence of high CDOM absorption. 


\section{Appendix A}

Table A1. Acronym list.

\begin{tabular}{|c|c|c|c|}
\hline Abbreviation & Description & Unit/Version & Category \\
\hline CHL, Chl $a$ & Phytoplankton pigments with chlorophyll $a$ as proxy & $\mathrm{mg} \mathrm{m}^{-3}$ & Water constituent \\
\hline SPM & Suspended particulate matter & $\mathrm{g} \mathrm{m}^{-3}$ & Water constituent \\
\hline CDOM, aCDOM & Coloured dissolved organic matter and its absorption measured at $440 \mathrm{~nm}$ & $\mathrm{~m}^{-1}$ & Water constituent \\
\hline YEL-BPA & Yellow substances and bleached particle absorption & $\mathrm{m}^{-1}$ & Water constituent \\
\hline AMORGOS & Accurate MERIS Ortho-Rectified Geo-location Operational Software & & Software \\
\hline BEAM & Earth Observation Toolbox and Development Platform & v.4.10.3 & Software \\
\hline ODESA & Optical data processor of the European Space Agency & & Software \\
\hline TACCS & Tethered attenuation coefficient chain-sensor & & Field radiometry instruments \\
\hline MERIS & MEdium Resolution Imaging Spectrometer & & Satellites and Sensors \\
\hline ENVISAT & ENVIronment SATellite & & Satellites and Sensors \\
\hline MEGS & MERIS ground segment development platform & v.8.1 & Level-2 processors \\
\hline FUB & Freie Universität Berlin Water processor & v.1.2.10 & Level-2 processors \\
\hline $\mathrm{C} 2 \mathrm{R}$ & Case 2 Regional & v.1.5.3 & Level-2 processors \\
\hline BOREAL & Lakes Boreal processor & v.1.5.3 & Level-2 processors \\
\hline ICOL & Improved contrast between ocean and land & v.2.9.1 & Level 1B data processing \\
\hline EQ & Equalization of coherent noise & & Level 1B data processing \\
\hline $\mathrm{SC}$ & Smile correction & & Level 1B data processing \\
\hline IOP & Inherent optical properties & & Optics and radiometry \\
\hline VIS & Visible light of the electromagnetic spectrum [380-750 nm] & $\mathrm{nm}$ & Optics and radiometry \\
\hline NIR & Near-infrared & $\mathrm{nm}$ & Optics and radiometry \\
\hline TOA & Top of atmosphere & & Geolocation \\
\hline MNB & Mean normalized bias & & Statistics \\
\hline $\mathrm{RMS}_{\mathrm{RD}}$ & Root mean squared of the relative differences & & Statistics \\
\hline
\end{tabular}




\section{The Supplement related to this article is available online at doi:10.5194/os-10-377-2014-supplement.}

Acknowledgements. This research was funded by the Swedish National Space Board (Dnr. 99/09) and the European Space Agency (ESA, contract no. 21524/08/I-OL). The authors would like to thank the staff at Askö Laboratory for support during field work. Great thanks are due to Gerald Moore for further developing the TACCS processor and advice on radiometric measurements and calibrations. Thanks are also due to the ODESA forum community, especially to Constant Mazeran, for valuable discussions and clarifications regarding the MEGS processor and Thomas Schroeder for answering questions regarding the architecture of FUB. Acknowledgements go to Helena Höglander, Therese Harvey and Ragnar Elmgren from Stockholm University, Ecology, Environment and Plant Sciences, for valuable contributions regarding the Swedish National Monitoring Data and descriptions of the Himmerfjärden sewage treatment plant nitrogen experiments. Thanks also go to ESA and ACRI-ST for developing ODESA, available at http://earth.eo.esa.int/odesa.

Edited by: O. Zielinski

\section{References}

ACRI-ST: The AMORGOS MERIS CFI (Accurate MERIS OrthoRectified Geo-location Operational Software) Software User Manual \& Interface Control Document, pO-ID-ACR-GS-0003, 2011.

ACRI-ST: ODESA software distribution, Quick start guide, oDESA-ACR-QSG, 2012.

Antoine, D. and Morel, A.: ATDB 2.7. Atmospheric Correction of the MERIS observations Over Ocean Case 1 waters, Tech. Rep. 5, Laboratoire D’Océanographie de Villefranche, 2011.

Attila, J., Koponen, S., Kallio, K., Lindfors, A., Kaitala, S., and Ylöstalo, P.: MERIS Case II water processor comparison on coastal sites of the northern Baltic Sea, Remote Sens. Environ., $128,138-149,2013$.

Babin, M.: COAstal Surveillance Through Observation of Ocean Colour (COAST-LOOC), Final Report, Project ENV4-CT960310, 2000

Bailey, S. W. and Werdell, P. J.: A multi-sensor approach for the on-orbit validation of ocean color satellite data products, Remote Sens. Environ., 102, 12-23, doi:10.1016/j.rse.2006.01.015, 2006.

Barker, K.: MERIS Optical Measurement Protocols. Part A: In situ water reflectance measurements, CO-SCI-ARG-TN-008, 2011.

Borges, A. V.: Do we have enough pieces of the jigsaw to integrate $\mathrm{CO}_{2}$ fluxes in the coastal ocean?, Estuaries, 28, 3-27, doi:10.1007/BF02732750, 2005.

Bourg, L. and Members of the MERIS Quality Working Group: MERIS 3rd data reprocessing. Software and ADF updates, Report no. A879.NT.008.ACRI-ST, contract No. 21091/07/I-OL, 2011.
Bouvet, M. and Ramino, F.: Equalization of MERIS L1b products from the 2nd reprocessing, Tech. Rep. ESA TN TECEEP/2009.521/MB, ESA, 2010

Carder, K. L., Hawes, S. K., Baker, K. A., Smith, R. C., Steward, R. G., and Mitchell, B. G.: Reflectance model for quantifying chlorophyll $\mathrm{a}$ in the presence of productivity degradation products, J. Geophys. Res.-Oceans, 96, 20599-20611, doi:10.1029/91JC02117, 1991.

Cristina, S. V., Goela, P., Icely, J. D., Newton, A., and Fragoso, B.: Assessment of the water-leaving reflectances of the oceanic and coastal waters using MERIS satellite products in Sagres off the southwest coast of Portugal, J. Coast. Res., available at: http: //hdl.handle.net/10400.1/1106, 1479-1483, 2009.

Darecki, M. and Stramski, D.: An evaluation of MODIS and SeaWiFS bio-optical algorithms in the Baltic Sea, Remote Sens. Environ., 89, 326-350, doi:10.1016/j.rse.2003.10.012, 2004.

Doerffer, R.: Protocols for the validation of MERIS water products - PO-TN-MEL-GS-0043, Tech. Rep. 1, GKSS Forschungszentrum Geesthacht, available at: https://earth.esa.int/workshops/ mavt_2003/MAVT-2003_801_MERIS-protocols_issue1.3.5.pdf (last access: 19 March 2014), 2002.

Doerffer, R.: ATBD 2.255. Alternative Atmospheric Correction Procedure for Case 2 Water Remote Sensing using MERIS, Algorithm Theoretical Basis Document (ATBD) Version 1.0, Helmholtz-Zentrum Geesthacht, 21502 Geesthacht, 2011.

Doerffer, R. and Schiller, H.: ATBD 2.12. Pigment index, sediment and gelbstoff retrieval from directional water leaving reflectances using inverse modelling technique. Doc. No. POTN-MEL-GS-0005, Algorithm Theoretical Basis Document (ATBD) 4, GKSS Forschungszentrum Geesthacht, Institute of Hydrophysics, 21502 Geesthacht Germany, 1997.

Doerffer, R. and Schiller, H.: The MERIS Case 2 water algorithm, Int. J. Remote Sens., 28, 517-535, doi:10.1080/01431160600821127, 2007.

Doerffer, R. and Schiller, H.: MERIS Lake Water Algorithm for BEAM, Algorithm Theoretical Basis Document (ATBD) Version 1.0, GKSS GmbH, 21502 Geesthacht, 2008.

Doerffer, R., Sorensen, K., and Aiken, J.: MERIS potential for coastal zone applications, Int. J. Remote Sens., 20, 1809-1818, doi:10.1080/014311699212498, 1999.

Elmgren, R.: Understanding Human Impact on the Baltic Ecosystem: Changing Views in Recent Decades, AMBIO, 30, 222-231, doi:10.1579/0044-7447-30.4.222, 2001.

European Space Agency: MERIS Product Handbook, available at: http://envisat.esa.int/handbooks/meris/ (last access: 3 June 2013), 2011.

Franzén, F., Kinell, G., Walve, J., Elmgren, R., and Söderqvist, T.: Participatory Social-Ecological Modeling in Eutrophication Management: the Case of Himmerfjärden, Sweden, Ecol. Soc., 16, 27, doi:10.5751/ES-04394-160427, 2011.

González Vilas, L., Spyrakos, E., and Torres Palenzuela, J. M.: Neural network estimation of chlorophyll a from MERIS full resolution data for the coastal waters of Galician rias (NW Spain), Remote Sens. Environ., 115, 524-535, doi:10.1016/j.rse.2010.09.021, 2011.

Gregg, W. W. and Conkright, M. E.: Global seasonal climatologies of ocean chlorophyll: Blending in situ and satellite data for the Coastal Zone Color Scanner era, J. Geophys. Res.-Oceans, 106, 2499-2515, 2001. 
Heim, B., Overduin, P., Schirrmeister, L., and Doerffer, R.: OCOC -from Ocean Colour to Organic Carbon, Proc. of the 2nd MERIS/(A)ATSR User Workshop, Frascati, Italy 22-26 September 2008 (ESA SP-666, November 2008), 2008.

IOCCG: Report 10. Atmospheric correction for remotely-sensed ocean-colour products, IOCCG, International Ocean-Colour Coordinating Group, Canada, CA, 2010.

Jeffrey, S. W. and Humphrey, G. F.: New spectrophotometric equations for determining chlorophylls a, b, c1 and c2 in higher plants, algae and natural phytoplankton, Biochemie und Physiologie der Pflanzen, 167, 191-194, 1975.

Kajiyama, T., D’Alimonte, D., and Zibordi, G.: Regional Algorithms for European Seas: A Case Study Based on MERIS Data, IEEE Geosci. Remote S., 10, 283-287, 2013.

Kirk, J. T. O.: Light and photosynthesis in aquatic environments, Cambridge University Press, 2nd Edn., 1994.

Koponen, S., Ruiz-Verdu, A., Heege, T., Heblinski, J., Sorensen, K., Kallio, K., Pyhälahti, T., Doerffer, R., Brockmann, C., and Peters, M.: Development of MERIS lake water algorithms. Validation report, ESRIN Contract No. 20436/06/I-LG, 2008.

Kowalczuk, P., Stedmon, C. A., and Markager, S.: Modeling absorption by CDOM in the Baltic Sea from season, salinity and chlorophyll, Mar. Chem., 101, 1-11, doi:10.1016/j.marchem.2005.12.005, 2006.

Kratzer, S.: Bio-optical Studies of Coastal Waters, Ph.D. thesis, University of Wales, Bangor. School of Ocean Sciences, Menai Bridge, Anglesey, LL59 5EY, UK, 2000.

Kratzer, S. and Tett, P.: Using bio-optics to investigate the extent of coastal waters: A Swedish case study, Hydrobiologia, 629, 169186, doi:10.1007/s10750-009-9769-x, 2009.

Kratzer, S. and Vinterhav, C.: Improvement of MERIS level 2 products in Baltic Sea coastal areas by applying the Improved Contracttrast between Ocean and Land processor (ICOL)-data analysis and, Oceanologia, 32, 211-236, 2010.

Kratzer, S., Brockmann, C., and Moore, G.: Using MERIS full resolution data to monitor coastal waters - A case study from Himmerfjärden, a fjord-like bay in the northwestern Baltic Sea, Remote Sens. Environ., 112, 2284-2300, doi:10.1016/j.rse.2007.10.006, 2008.

Kutser, T.: Quantitative detection of chlorophyll in cyanobacterial blooms by satellite remote sensing, Limnol. Oceanogr., 49, 2179-2189, 2004.

Kutser, T., Paavel, B., Metsamaa, L., and Vahtmäe, E.: Mapping coloured dissolved organic matter concentration in coastal waters, Int. J. Remote Sens., 30, 5843-5849, 2009.

Laur, H.: ENVISAT and ERS missions, in ATMOS 2012, Advances in Atmospheric Science and Applications, 1822 June 2012, Bruges, Belgium, European Space Agency, available at: http://congrexprojects.com/docs/12m06_docs $2 / 3$ laur--envisat-ers.pdf?sfvrsn=2 (last access: 1 June 2013), 2012.

Leppèaranta, M. and Myrberg, K.: Physical Oceanography of the Baltic Sea, Springer Praxis Books, Springer Berlin Heidelberg, doi:10.1007/978-3-540-79703-6, 2009.

Maslowski, W. and Walczowski, W.: Circulation of the Baltic Sea and its connection to the Pan-Arctic region - a large scale and high-resolution modeling approach, Boreal Environ. Res., 7, 319-325, 2002.

MERIS_ESL: MERIS smile effect characterisation and correction, Tech. rep., ESA, technical note, 2008.
Mobley, C. D.: Light and Water, Radiative Transfer in Natural Waters, Vol. 592, Academic Press, 1994.

Moore, G., Icely, J., and Kratzer, S.: Field Inter-comparison and validation of in-water radiometer and sun photometers for MERIS validation, Proceedings of the ESA Living Planet Symposium, Special Publication SP-686, 2010.

Morel, A. and Prieur, L.: Analysis of variations in ocean color, Limnol. Oceanogr., 22, 709-722, doi:10.4319/lo.1977.22.4.0709, 1977.

Nelson, N. B. and Siegel, D. A.: The Global Distribution and Dynamics of Chromophoric Dissolved Organic Matter, Annu. Rev. Mar. Sci., 5, 447-476, doi:10.1146/annurev-marine-120710100751, 2013.

Ohde, T., Siegel, H., and Gerth, M.: Validation of MERIS Level-2 products in the Baltic Sea, the Namibian coastal area and the Atlantic Ocean, Int. J. Remote Sens., 28, 609-624, doi:10.1080/01431160600972961, 2007.

Park, Y., Van Mol, B., and Ruddick, K.: Validation of MERIS water products for Belgian coastal waters, in: Proceedings of MERIS and AATSR calibration and geographical validation validation workshop, 1, ESA, Frascati, 2004.

Parsons, T. R., Maita, Y., and Lalli, C. M.: A manual of chemical and biological methods for seawater analysis, XIV, Pergamon Press, Oxford, UK, 1984.

Philipson, P., Kratzer, S., Krusper, A., and Strömbeck: Final report - Satellite products development for water quality monitoring in the great lakes and Himmerfjärden, 2009.

Prieur, L. and Sathyendranath, S.: An Optical Classification of Coastal and Oceanic Waters Based on the Specific Spectral Absorption Curves of Phytoplankton Pigments, Dissolved Organic Matter, and Other Particulate Materials, Limnol. Oceanogr., 26, 671-689, 1981.

Reinart, A. and Kutser, T.: Comparison of different satellite sensors in detecting cyanobacterial bloom events in the Baltic Sea, Remote Sens. Environ., 102, 74-85, doi:10.1016/j.rse.2006.02.013, 2006.

Roesler, C. S. and Boss, E.: In Situ Measurement of the Inherent Optical Properties (IOPs) and Potential for Harmful Algal Bloom Detection and Coastal Ecosystem Observations, in: Real-time Coastal Observing Systems for Marine Ecosystem Dynamics and Harmful Algal Blooms. Theory, instrumentation and modelling, edited by: Babin, M., Roesler, C., and Cullen, J. J., UNESCO Publishing, Paris, 2008.

Santer, R. and Zagolski, F.: ICOL ATBD, Tech. Rep. version 0.1, Université du Littoral, Wimereux, France, 2007.

Santer, R. and Zagolski, F.: ICOL-Improve contrast between ocean \& land, ATBD-The MERIS Level 1-C, Tech. Rep. version 1.1, Université du Littoral, Wimereux, France, 2009.

Schroeder, T., Behnert, I., Schaale, M., Fischer, J., and Doerffer, R.: Atmospheric correction algorithm for MERIS above case-2 waters, Int. J. Remote Sens., 28, 1469-1486, doi:10.1080/01431160600962574, 2007a.

Schroeder, T., Schaale, M., and Fischer, J.: Retrieval of atmospheric and oceanic properties from MERIS measurements: A new Case2 water processor for BEAM, Int. J. Remote Sens., 28, 56275632, doi:10.1080/01431160701601774, 2007b.

Schwarz, J., Kowalczuk, P., Kaczmarek, S., Cota, G., Mitchell, B., Kahru, M., Chavez, F., Cunningham, A., McKee, D., Gege, P., Kishino, M., Phinney, D., and Raine, R.: Two models for absorp- 
tion by coloured dissolved organic matter (CDOM), Oceanologia, 44, 209-241, 2002.

Sørensen, K., Grung, M., and Röttgers, R.: An intercomparison of in vitro chlorophyll a determinations for MERIS level 2 data validation, Int. J. Remote Sens., 28, 537-554, doi:10.1080/01431160600815533, 2007.

Stramski, D., Boss, E., Bogucki, D., and Voss, K. J.: The role of seawater constituents in light backscattering in the ocean, Prog. Oceanogr., 61, 27-56, doi:10.1016/j.pocean.2004.07.001, 2004.

Strickland, J. and Parsons, T.: A practical handbook of seawater analysis, Fisheries Research Board of Canada Series, Fisheries Research Board of Canada, 1972.

Vaičiūtè, D., Bresciani, M., and Bučas, M.: Validation of MERIS bio-optical products with in situ data in the turbid Lithuanian Baltic Sea coastal waters, J. Appl. Remote Sens., 6, 063568.1063568.20, 2012.
Zhang, T.: Retrieval of oceanic constituents with artificial neural network based on radiative transfer simulation techniques, Ph.D. thesis, Freie Universität, Berlin, 2003.

Zibordi, G., Ruddick, K., Ansko, I., Moore, G., Kratzer, S., Icely, J., and Reinart, A.: In situ determination of the remote sensing reflectance: an inter-comparison, Ocean Sci., 8, 567-586, doi:10.5194/os-8-567-2012, 2012.

Zibordi, G., Mélin, F., Berthon, J.-F., and Canuti, E.: Assessment of MERIS ocean color data products for European seas, Ocean Sci., 9, 521-533, doi:10.5194/os-9-521-2013, 2013. 